\title{
Mycoparasite Hypomyces odoratus infests Agaricus xanthodermus fruiting bodies in nature
}

\author{
Kiran Lakkireddy ${ }^{1,2+}$, Weeradej Khonsuntia ${ }^{1,2,3+}$ and Ursula Kües ${ }^{1,2^{*}}$ (D)
}

\begin{abstract}
Mycopathogens are serious threats to the crops in commercial mushroom cultivations. In contrast, little is yet known on their occurrence and behaviour in nature. Cobweb infections by a conidiogenous Cladobotryum-type fungus identified by morphology and ITS sequences as Hypomyces odoratus were observed in the year 2015 on primordia and young and mature fruiting bodies of Agaricus xanthodermus in the wild. Progress in development and morphologies of fruiting bodies were affected by the infections. Infested structures aged and decayed prematurely. The mycoparasites tended by mycelial growth from the surroundings to infect healthy fungal structures. They entered from the base of the stipes to grow upwards and eventually also onto lamellae and caps. Isolated H. odoratus strains from a diseased standing mushroom, from a decaying overturned mushroom stipe and from rotting plant material infected mushrooms of different species of the genus Agaricus while Pleurotus ostreatus fruiting bodies were largely resistant. Growing and grown A. xanthodermus and P. ostreatus mycelium showed degrees of resistance against the mycopathogen, in contrast to mycelium of Coprinopsis cinerea. Mycelial morphological characteristics (colonies, conidiophores and conidia, chlamydospores, microsclerotia, pulvinate stroma) and variations of five different $\mathrm{H}$. odoratus isolates are presented. In pH-dependent manner, $H$. odoratus strains stained growth media by pigment production yellow (acidic $\mathrm{pH}$ range) or pinkish-red (neutral to slightly alkaline $\mathrm{pH}$ range).
\end{abstract}

Keywords: Mycopathogen, Hypomyces, Agaricus, Mushrooms, Conidiation, Microsclerotia

\section{Introduction}

Commercially cultivated mushrooms can be attacked by distinct mycoparasites such as the edible Agaricus bisporus by the ascomycetes Lecanicillium fungicola, Mycogone perniciosa (teleomorph Hypomyces perniciosus), and Cladobotryum dendroides (teleomorph Hypomyces rosellus) which cause dry bubble, wet bubble and cobweb disease, respectively (Largeteau and Savoie 2010; Berendsen et al. 2010; Carrasco et al. 2017). Such infections can result in severe crop losses, particularly in later flushes, if hygienic standards during cultivation are not high. Infections might originate from contaminated soil or spawn

\footnotetext{
*Correspondence: ukuees@gwdg.de

${ }^{\dagger}$ Kiran Lakkireddy and Weeradej Khonsuntia contributed equally to the work

${ }^{1}$ Department of Molecular Wood Biotechnology and Technical Mycology, Büsgen-Institute, Georg-August-University, Göttingen, Germany Full list of author information is available at the end of the article
}

and the fungi might be introduced into mushroom casing in the form of spores or mycelium (Adie et al. 2006; Soković and Van Griensven 2006; Szumigaj-Tarnowska et al. 2015; Carrasco et al. 2017).

Lecanicillium fungicola not only infects the generative stage of $A$. bisporus but at all phases of fruiting body development (North and Wuest 1993; Calonje et al. 2000; Bernardo et al. 2004; Largeteau et al. 2007; Nunes et al. 2017). Depending on the developmental stage that becomes infected, disease symptoms range from totally undifferentiated spherical masses formed together by mycelia of host and pathogen ("dry bubble"), over partial disruption of stipe and cap tissues resulting in stipe deformations ("stipe blowout") to small necrotic lesions in the cap ("spotty cap") (North and Wuest 1993; SolerRivas et al. 2000; Largeteau et al. 2007, Largeteau and Savoie 2010; Bailey et al. 2013). Early infection of fruiting body initials by $M$. perniciosa also leads to the formation
Springer Open (c) The Author(s) 2020. This article is licensed under a Creative Commons Attribution 4.0 International License, which permits use, sharing, adaptation, distribution and reproduction in any medium or format, as long as you give appropriate credit to the original author(s) and the source, provide a link to the Creative Commons licence, and indicate if changes were made. The images or other third party material in this article are included in the article's Creative Commons licence, unless indicated otherwise in a credit line to the material. If material is not included in the article's Creative Commons licence and your intended use is not permitted by statutory regulation or exceeds the permitted use, you will need to obtain permission directly from the copyright holder. To view a copy of this licence, visit http://creativeco mmons.org/licenses/by/4.0/. 
of undifferentiated hyphal masses ("sclerodermoid mushrooms"). These "wet bubbles" are first white and spongy. Then, they turn brownish and may be covered by ambercoloured liquid excretions. Mushroom deformations and cap spotting result from infections at later developmental stages (Fletcher et al. 1995; Umar and Van Griensven 1999; Umar et al. 2000; Glamoclija et al. 2008; Kouser and Shah 2013; Zhang et al. 2017). The soil inhabiting $C$. dendroides covers all stages of fruiting bodies in form of coarse white mycelium ("cobweb") under massive conidiospore production. Overgrown mushrooms eventually rot and collapse. Further symptoms linked to cobweb disease are brown spotting on caps instigated by germinating spores (Bhatt and Singh 2002; Potočnik 2006; Parrag et al. 2014; Carrasco et al. 2017). In recent time, other Cladobotryum species (mainly C. mycophilum, teleomorph Hypomyces odoratus; C. varium, teleomorph Hypomyces aurantius) have more often been reported to cause cob-web diseases including cap spotting and patching on A. bisporus (McKay et al. 1999; Grogan and Gaze 2000; Back et al. 2010, 2012b; Lee et al. 2011; Sharma et al. 2015; Carrasco et al. 2016, 2017; Chakwiya et al. 2019). According to McKay et al. (1999), Grogan (2006) and Tamm and Põldmaa (2013), when H. odoratus occurs in mushroom farms, it is quite often misidentified under the name $H$. rosellus. The sexual fruiting bodies (perithezia) cannot easily be differentiated morphologically between the species unlike their conidiophores with the asexual conidia (Rogerson and Samuels 1993, 1994). Asexual strain features together with molecular data are therefore used to define species (Kirschner et al. 2007; Põldmaa 2011; Tamm and Põldmaa 2013; Gea et al. 2019).

The different mycopathogens are not restricted to $A$. bisporus but may affect also other commercially cultivated species. Incidences of $L$. fungicola disease were reported for other Agaricus species (Gea et al. 2003) and Pleurotus ostreatus (Marlowe and Romaine 1982). M. perniciosa is shown to also infect Pleurotus eryngii and Pleurotus nebrodensis as well as Volvariella volvaceae, with the result of fruiting body malformations (Sisto et al. 1997; Sharma and Kumar 2000; Carrasco et al. 2017). Aggressive cobweb infections by Cladobotryum species were described for cultured Calocybe indica (Sharma et al. 2015), Coprinus comatus (Wang et al. 2015), Flammulina velutipes (Kim et al. 1999; Back et al. 2012b), Ganoderma tsugae (Kirschner et al. 2007), Hypsizygus marmoreus (Back et al. 2012a, b, 2015), Pleurotus sajorcaju (Sharma et al. 2015), P. eryngii (Kim et al. 1998, 2014; Gea et al. 2011, 2016, 2017; Back et al. 2012b), and $P$. ostreatus (Pérez-Silva and Guevara 1999; Gea et al. 2019).
While attention is paid on pathogen infections in commercial mushroom cultures due to the high economic interest, infection events observed in nature are scattered and usually not deeply described. In nature, an association with basidiomycete fruiting bodies and verticillium-like anamorphs (conidiophores are verticillate with whorls of few to several phialides which give rise to the phialoconidia) can help to identify potential mycopathogens (Gray and Morgan-Jones 1980; Zare and Gams 2008; Rogerson and Samuels 1989, 1993, 1994; Põldmaa and Samuels 1999; Põldmaa 2003; Tamm and Põldmaa 2013; Chakwiya et al. 2019). From the wild, $L$. fungicola has been isolated from fruiting bodies of Agaricales (e.g. Marasmiellus ramealis, Hypholoma capnoides and Laccaria laccata) and of decaying samples of Thelephora terrestris from the Thelephorales. Lecanicillium flaccidum from the same species complex was obtained from basidiocarps of Coltricia perennis of the Hymenochaetales and of Gomphidius glutinosus from the Boletales, and of decaying samples of Russula nigricans of the Russulales (Zare and Gams 2008). Incidences of Hypomyces/Cladobotryum infections appear to be more common. C. dendroides and C. mycophilum have a broad host range and have been isolated from mushrooms of varied species of Agaricales, Boletales, Hymenochaetales, Polyporales, Russulales, Telephorales and others. However, there are several more mycopathogens between the paraphyletic Hypomyces/Cladobotryum species group, several of which are producing yellow to red-coloured pigments and some of which have a more restricted host range (Gray and Morgan-Jones 1980; Sohi and Upadhyay 1986; Rogerson and Samuels 1989, 1993, 1994; Helfer 1991; Põldmaa and Samuels 1999; Douhan and Rizzo 2003; Põldmaa 2003; Valdez and Douhan 2012; Tamm and Põldmaa 2013; Marzuko et al. 2015; Wang et al. 2015; Zare and Gams 2016). In particular, orange-red lobster mushrooms are fruiting bodies of Russula, Lactarius and Lactifluus species from the Russulales which are infested by staining Hypomyces lactifluorum and are collected and commercially marketed as culinary delicacy in Mexico and Northern America (Laperriere et al. 2018).

In this report, we describe our observations on infestations of Agaricus xanthodermus fruiting structures in nature with strongly sporulating ascomycetous mycopathogens. We isolated mycopathogenic strains from infested material and describe their morphology and molecular identity with ITS sequences as $H$. odoratus $/ C$. mycophilum. Furthermore, we performed infection studies with vegetative mycelium and fruiting structures of different basidiomycetous species. 


\section{Materials and methods}

\section{Mushroom observations, collection and fungal strain} isolation

Mushrooms of $A$. xanthodermus growing underneath a Pseudotsuga menzii tree on the north side next to building Büsgenweg 5 of the Faculty of Forest Sciences and Forest Ecology (latitude 41.55933; longitude 9.95722) on the grounds of the North Campus of the University of Göttingen were usually observed and photographed at noon (at about 13 to 14 o'clock). Climate data (temperature and humidity) were routinely collected on the grounds through a hygro-thermo transmitter (Adolf Thies GmbH \& Co. KG, Thies Clima, Göttingen, Germany). Mushrooms were identified by morphology using Breitenbach and Kränzlin (1995).

Crippled and decaying mushrooms were collected as well as rotting grass/moss samples with obvious white fungal mycelium. The samples were directly brought to a classroom laboratory and photographed by an IXUS 115 HS digital camera (Canon, Krefeld, Germany). For enlarged views, a M205 FA stereomicroscope with an integrated CF420 camera was used and the Leica Application Suite v3.8 software (Leica, Wetzlar, Germany). Samples of infesting mycelium from the cap of a crippled mushroom and mycelial samples of isolated cultures were observed with an Axioplan 2 imaging microscope (Carl Zeiss, Göttingen, Germany) equipped with a Soft Imaging System ColorView II digital camera. Digital photos taken were processed with the Soft Imaging System analySIS software (EMSIS, Münster, Germany). Size parameters were measured with the Arbitrary Distance function of the program and Excel (Microsoft, Redmond, WA) was used for calculations.

To isolate the basidiomycete, small mycelial samples were aseptically taken from the inner stipe regions of a healthy mushroom, and tissues were transferred onto MEA (2\% malt extract, $1 \%$ agar; initial pH 5.0) plates with added antibiotics (ampicillin $100 \mu \mathrm{g} / \mathrm{ml}$, kanamycin $50 \mu \mathrm{g} / \mathrm{ml}$, tetracycline $10 \mu \mathrm{g} / \mathrm{ml}$, chloramphenicol $20 \mu \mathrm{g} /$ $\mathrm{ml}$ and streptomycin $100 \mu \mathrm{g} / \mathrm{ml}$ ) as described formerly in Badalyan et al. (2011). To isolate the potential mycopathogens, foreign mycelia were taken from outer infested stipe and cap regions as well as from a grass/moss sample and transferred onto MEA plates supplemented with antibiotics. Plates were incubated at room temperature (RT) in the classroom. Growing mycelial samples were transferred for strain isolation and colony observations onto fresh MEA and YMG/T (0.4\% yeast extract, $1 \%$ malt extract, $0.4 \%$ glucose, $0.001 \%$ tryptophan, $1 \%$ agar; Granado et al. 1997; initial pH 6) for growth at RT. Plastic Petri dishes $(9 \mathrm{~cm}$ in $\varnothing)$ with vents were used. Yeast extract (LP0021) and malt extract (L39) were from Oxoid
(Basingstroke, UK), agar (Nr. 11396) from Serva (Heidelberg, Germany).

The isolated dikaryotic mycelium of $A$. xanthodermus (strain KKRL1) and the five different mycopathogen isolates (AscoA1, AscoB1, AscoC1, AscoD1, AscoE1) of this study were deposited in the DSMZ (Deutsche Sammlung von Mikroorganismen und Zellkulturen $\mathrm{GmbH}$ ) strain collection in Braunschweig (Germany) under Catalog numbers DSM 111245 (KKRL1) to DSM 111250 (AscoA1 to AscoE1), respectively.

\section{Colony characterisation}

Cultures were grown at RT if not otherwise stated. Cultures were photographed with the IXUS 115 HS digital camera. $\mathrm{pHs}$ of culture medium were estimated with $\mathrm{pH}$ indicator strips which were dipped into squeezed agar pieces cut out from fresh and from mycelium overgrown medium. Mycelial samples with conidiophores, conidia or chlamydospores were observed under a Zeiss Axioplan 2 imaging microscope, digital photos were taken and size parameters measured with the analySIS software as described above. Diameters of chlamydospores as of microsclerotia and dense mycelial patches were measured crosswise in two directions and averages were calculated from all data. White mycelial patches were analysed in digital photos of complete cultures and microsclerotia using colony views of older cultures with collapsed aerial mycelium as photographed under the M205 FA stereomicroscope. Conidia from fully grown whole cultures were harvested from the culture surfaces as described in Kertesz-Chaloupková et al. (1998), spores attached to the lids of Petri dishes were washed off with sterile water and added to the spores harvested from the colony surfaces and total spores were counted using a hematocytometer.

\section{ITS sequencing}

Genomic DNA was isolated from mushroom samples taken from outside and from mycelium in culture (Zolan and Pukkila 1986). ITS sequences of basidiomycetes were PCR-amplified with primers ITS1 (TCCGTAGGTGAA CCTGCGG) and ITS4 (TCCTCCGCTTATTGATAT GC) (White et al. 1990) and of ascomycetes with primers ITS-1* (TCCGTTGGTGAACCAGCGG) (Waalwijk et al. 1996) and ITS4 and analyzed as described before (Naumann et al. 2007). Gene sequences were deposited in GenBank under the Accession numbers KX098646-KX098654.

\section{Mushroom infestation tests}

Commercial mushrooms of $A$. bisporus (cap $\varnothing 3.7$ to $5.7 \mathrm{~cm}$ ) and $P$. ostreatus (cap width between 2.4 and $6.7 \mathrm{~cm}$ ) were purchased from a local supermarket. $A$. bisporus fruiting bodies were longitudinally cut into 
halves and transferred into sterile crystal dishes $(18.5 \mathrm{~cm}$ in $\varnothing, 4.5 \mathrm{~cm}$ in height) with the cut side alternatively positioned to the top or to the bottom of the dish. Other A. bisporus mushrooms were used in whole in erect condition. P. ostreatus fruiting bodies were used either in whole or as halves in upside-top (lamellae oriented down) and in upside-down position (lamellae oriented to the top). Non-injured caps or cuts of caps or cut or non-cut sides of stipes of the fruiting bodies of $A$. bisporus and either caps or stipes of $P$. ostreatus were infested with small freshly grown MEA agar pieces of mycelial isolates, the crystal dishes were closed by their lids and incubated at RT. Every 12 to $24 \mathrm{~h}$, mushrooms were inspected and photographed. For every isolate, at least 35 mushroom samples of $A$. bisporus and 25 mushroom samples of $P$. ostreatus were tested in at least 4 rounds of experiments.

Further, Agaricus mushrooms collected in September 2015 from the wild in other places in GöttingenWeende/-Nordstadt were transferred into sterile glass jars and infested either on the cap or at the bottom of the stipe by small MEA agar pieces with freshly grown mycelial samples. Mushroom identities were determined by morphological means (Breitenbach and Kränzlin 1995) and ITS sequencing as A. xanthodermus (KX098653) and Agaricus sp. section Arvenses (KX098654).

\section{Culture infestation tests}

Mycelial cultures of Coprinopsis cinerea strain AmutBmut (A43mut, B43mut, pab1-1; Kertesz-Chaloupková et al. 1998), P. ostreatus monokaryon Pc9 (CECT20311), and of the isolated dikaryon KKRL1 of $A$. xanthodermus were prepared by inoculating one or two small freshly grown mycelial samples in the middle or at equal distances distributed on MEA or YMG/T plates and incubating them for vegetative growth at $37{ }^{\circ} \mathrm{C}(C$. cinerea for subsequent grown mycelial challenge tests) or room temperature (RT, about $22{ }^{\circ} \mathrm{C}$, used for other species in all grown mycelial challenge tests). Once a basidiomycete mycelium was fully established, a culture was challenged with two ca. $1 \times 1 \mathrm{~mm}$ small inocula of freshly grown MEA agar pieces of a mycelial isolate to be tested by placing them onto the already grown basidiomycete mycelium $2 \mathrm{~cm}$ apart from the basidiomycete inoculum. The dual cultures were further incubated at RT and observed on daily basis for at least 20 days and in some instances for up to 2 months. Plates were photographed by an IXUS 115 HS digital camera. Five (A. xanthoder$m u s$ ) to six repeats (others) with two to three plates each were followed up per strain combination and MEA or YMG/T medium. Mycelial samples were observed under a Zeiss Axioplan 2 imaging microscope (Carl Zeiss, Göttingen, Germany).

In other sets of experiments (mycelial confrontation tests), basidiomycetes were inoculated on MEA or YMG/T medium $1.5 \mathrm{~cm}$ apart from the edge of a Petri dish (and pregrown when needed; see "Results" section), and the mycelial test strains $1.5 \mathrm{~cm}$ apart from the edge of the opposite side of the Petri dish. All plates were incubated at RT and observed for about a month and more after they were fully overgrown by the two mycelia. Five (A. xanthodermus) to six repeats (others) with two to three plates each were followed up per combination on MEA medium or YMG/T medium. Plates were regularly observed and photographed by an IXUS 115 HS digital camera and under a Zeiss Stemi 2000-C Binocular (Carl Zeiss, Göttingen, Germany). Presence of conidiophores and -spores of test isolates and hyphae of basidiomycetes were followed up by observing small mycelial samples from confrontation zones under a Zeiss Axioplan 2 imaging microscope.

\section{Results}

\section{Mushroom development of Agaricus xanthodermus in nature}

Since 2012, we observed every year but in 2018 and 2019 as 2 years with very dry hot summers that multiple white fruiting bodies of an Agaricus species appeared singly or in small loose groups variably in the months June to November in the thick layer of needle and cone litter underneath a $P$. menziesii (Douglas fir) tree and in the nearby grass of the surrounding meadow on the North Campus of Göttingen University (Fig. 1a). Initially, we noticed the conspicuous mushrooms either in still closed or in already opened conditions. Later with better attention we also saw smaller primordia $(<1 \mathrm{~cm}$

\footnotetext{
(See figure on next page.)

Fig. 1 Agaricus xanthodermus fruiting bodies. a Mushrooms (marked by arrows) underneath a Pseudotsuga menziesii tree on the 3rd of September 2015. b Drum-stick-like young mushrooms: the left one is grown to full size (the arrow points to the partial veil underneath the cap). c Mushroom opening and $\mathbf{d}$ fully opened mushroom with vestiges of the partial veil at the edge of the opened cap and a skirt-like annulus around the stipe (marked by arrows). e-I Diseased crippled young mushroom with split stipe and cap and an infested primordium partially covered by a fluffy foreign mycelium (marked by an arrow) on 1st of September 2015 at the day of detection (e), 1 day after (f, $\mathbf{h}$; the arrow points to partial veil still attached to cap tissues), 2 days after ( $\mathbf{g}$, $\mathbf{i}$; note the pinkish still healthy lamellae in $\mathbf{i}$ ) and 3 days after $\mathbf{j}$ ), when the mushroom was harvested (k; note the now brown colour of the lamellae and the white foreign mycelium which covers the crippled stipe and grows onto the lamellae). After harvest, white mycelium was seen spread over the needle and cone litter layer, the decayed primordium and a cone from the Douglas fir underneath (I)
} 

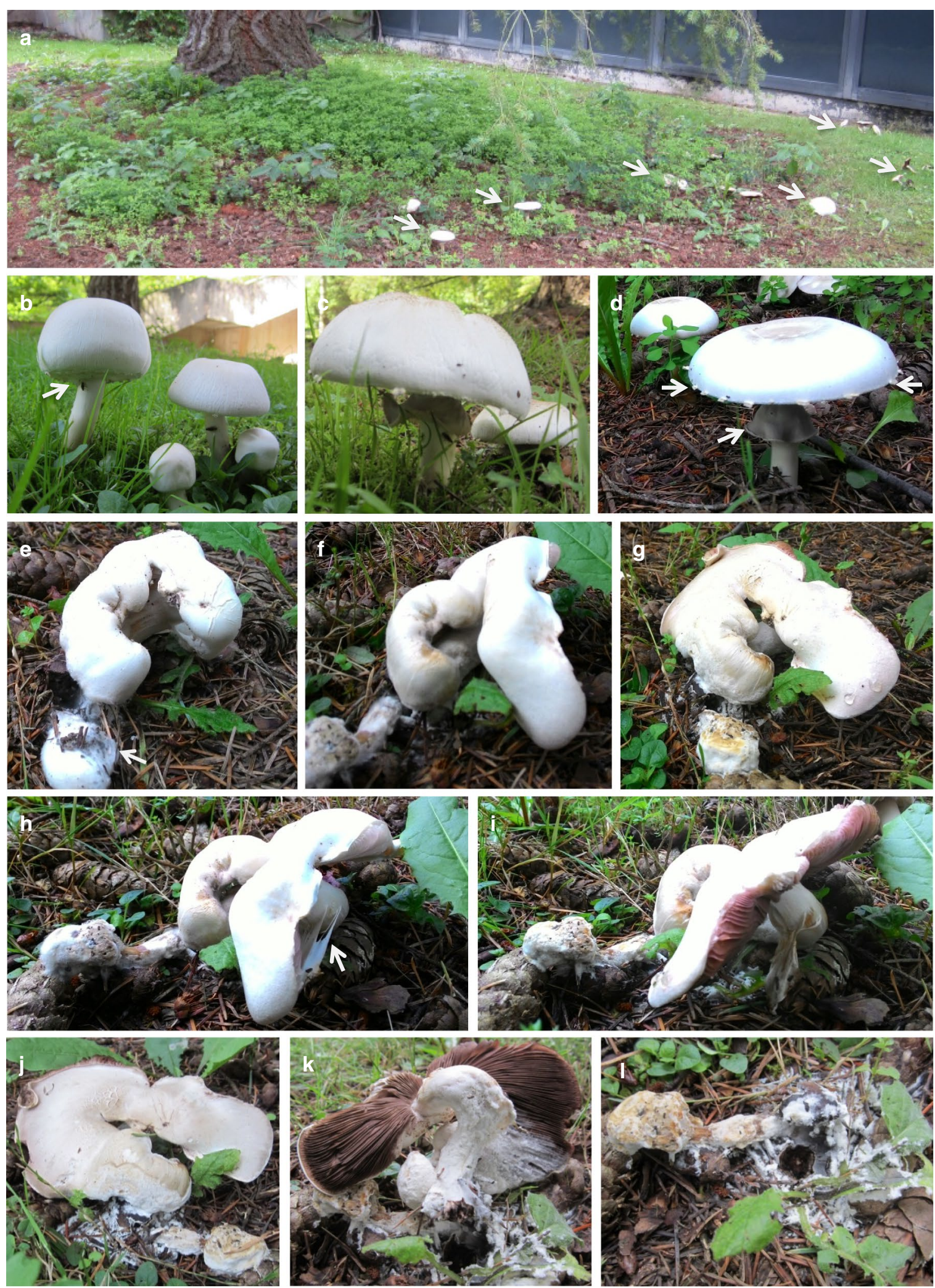
in $\varnothing)$ emerging through the soil from broken ground. Mushroom production appeared to correlate with 1 to 3 prior days of high humidity triggered by good rainfall (about $80 \%$ and 95\% humidity at days and nights) when temperatures reduced with the rainfall by about 5 to highest $10^{\circ}$ from prior day time temperature values which were between 18 and to up to $30^{\circ} \mathrm{C}$ at former warmer days (the actual temperatures depended on the time of the year). Spherical primordia were observed aboveground 2 to 4 days after the inducing days of high humidity and reduced temperature, still closed mushrooms with lengthened stipes ("drum-sticks") 4 to 8 days and opened mushrooms 10 to over 20 days after the rainfalls, when the days following induction were sunny and again warmer in temperature by an increase of 2 to $5^{\circ}$ and when humidity values differed between night (ca. $80-95 \%$ humidity) and day periods (ca. 60-85\% humidity). Fruiting body development continued usually in a temperature range from 15 to slightly above $20^{\circ} \mathrm{C}$. However, depending on the month there were also exceptional days encountered in later fruiting body development with temperatures up to $30^{\circ} \mathrm{C}$.

We observed round ball-like primordia (about $1.5-2 \mathrm{~cm}$ in $\varnothing$ ) on the floor and closed young white mushrooms that had a drum-stick shape and were generated from the spherical primordia by stipe growth and increase in cap size. Growth from a spherical primordium into a full-sized drum-stick-like young mushroom took several days, 2 to 3 days at warmer days $\left(18-22{ }^{\circ} \mathrm{C}\right)$, while it slowed down up to 6 to 8 days at colder temperature $\left(12-15{ }^{\circ} \mathrm{C}\right)$. Fully grown drum-sticks were up to 10 to $12 \mathrm{~cm}$ tall with a cap diameter of about 3 to $5 \mathrm{~cm}$ and a white partial veil at the underside of the cap that covered the lamellae (Fig. 1b). During maturation in the following 2 days, the white partial veil perforated with cap extension at the edge of the pileus. The remaining connections ripped apart with further cap opening and gave the stretched pileus a gear-wheel appearance by toothlike vestiges (Fig. 1c, d). With the ripping, the partial veil stayed first as a well-shaped skirt-like white annulus around the stipe (about 1.0 to $1.5-\mathrm{cm}$ in $\varnothing$, with the lower base somewhat swollen) at a distance of about 2 to $2.5 \mathrm{~cm}$ beneath the cap, but it degenerated with time over the following days. Opened caps were about 10 to $13 \mathrm{~cm}$ in diameter. On the upper surfaces towards the centres of the pilei were small yellowish to light brown scales. With cap opening, the densely arranged masses of initially pinkish thin lamellae (over 60 full length primary lamellae per cap with 5 to 7 secondary lamellae in between) turned quickly dark brown. Within 2 to 3 days, the cap colour turned pale-greyish and, slowly over 10 to 15 days, the open matured mushrooms grew old. The brown thick-walled smooth basidiospores (examples can be seen in Fig. $2 \mathrm{~m}$ ) measured in average $5.05 \pm 0.5 \times 3.89 \pm 0.63 \mu \mathrm{m}(\mathrm{n}=21)$.

By mushroom morphology and spore sizes, our morphological observations on the mushrooms concur with the descriptions by Breitenbach and Kränzlin (1995) for A. xanthodermus. However, strong yellow coloration upon injury of stems as typical for the species was first not noted; a faint yellow colour was seen on scratched freshly harvested mushroom stipes in September 2016 and again in July and more intensively in August 2017. The odour of healthy mushrooms of the colony was rather a faint mushroom scent than the typical pungent phenol odour of the species (Gill and Strauch 1984; Petrova et al. 2007) which in contrast was noticed by us for other A. xanthodermus colonies in the GöttingenWeende area. Lack of both parameters together initially lead to a misidentification as Agaricus macrosporus by its very similar mushroom shapes and sizes (Lakkireddy et al. 2016). The species identity A. xanthodermus of the mushroom colony underneath the $P$. menzii tree was here confirmed by sequencing ITS DNA which was PCRamplified from genomic DNA of a stipe of a mushroom harvested on 4th of September 2015. The established sequence (KX098652) was 99 and 100\% identical to $A$. xanthodermus sequences AY484689 and DQ182529.1 from GenBank (Geml et al. 2004; Kerrigan et al. 2005).

\section{Diseased mushrooms of Agaricus xanthodermus in nature}

On 1st of September 2015, among several normal healthy fruiting bodies, we noticed a crippled young mushroom at the late drum-stick state that had a bended deformed stipe and a split cap (Lakkireddy et al. 2016). A directly neighboured primordial mushroom had dropped and was half-covered by a mycelial white network that extended over the stipe onto the edges of the cap of the other crippled individual (Fig. 1e). Over the next 2 days, the still healthy parts of the cap of the crippled mushroom extended in size to expose the pinkish lamellae while the primordial mushroom degenerated into an amorphous clump under actions of the foreign mycelium (Fig. 1f-i). As seen a day later, cap tissues of the crippled mushroom quickly aged, probably accelerated through the presence of the foreign mycelium. A thick mycelial layer of a fungal infestation was present at the side of the cap that was closer to the ground (Figs. 1j, 2a, b) and as cover over the stipe of the mushroom (Figs. 1k, 2c, d) from which it grew onto the lamellae (Fig. 2d-i). The harvested infected mushroom had an unpleasant smell. Sequencing of ITS DNA (KX098651) PCR-amplified from mushroom tissues again confirmed $A$. xanthodermus as the species identity.

Conidiophores with oblong spores were obvious in thick older mycelium grown on the upper side of 

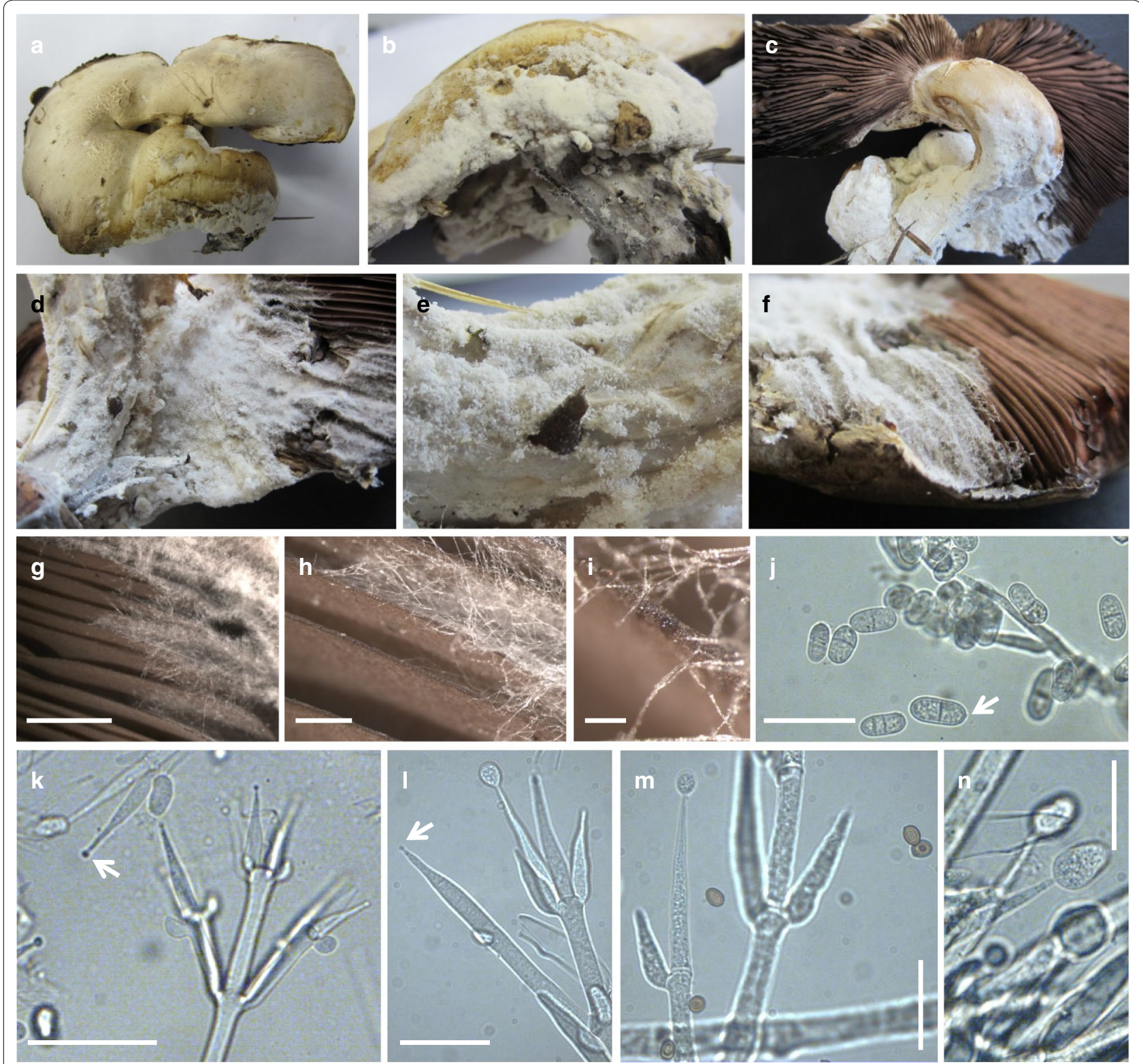

Fig. 2 Diseased crippled Agaricus xanthodermus fruiting body. $\mathbf{a}, \mathbf{b}$ The upper surface of the cap, $\mathbf{c}, \mathbf{d}$ the surface of the bended stipe, and $\mathbf{e}$, $\mathbf{f}$ parts of the lamellae are overgrown by foreign mycelium with conidiophores visible as white flocks in the aerial mycelium (d). $\mathbf{g}$-i For infestation of the lamellae, the foreign mycelium grew first over their edges, with conidiophore production starting about 6 to $7 \mathrm{~mm}$ behind the growth front ( $\mathbf{g}$; see white flocks at the right side of the photo). $\mathbf{j}-\mathbf{n}$ Conidia and conidiophores in mycelial samples taken for microscopy from the lamellae. Note the blastic generation of conidiospores at the tips of phialides (arrows in $\mathbf{k}-\mathbf{I}$ ) and dehiscence scars (basal hilum) at the spores (see arrow in $\mathbf{j}$ ) and also the small brown basidiospores of the host ( $\mathbf{m})$. Sizes bars correspond to $5 \mathrm{~mm}(\mathbf{g}), 1 \mathrm{~mm}(\mathbf{h}), 200 \mu \mathrm{m}(\mathbf{i}), 50 \mu \mathrm{m}(\mathbf{k})$ and $20 \mu \mathrm{m}(\mathbf{j}, \mathbf{I}-\mathbf{n})$

the cap, on the stipe and the lamellae (Fig. 2b-g). We microscoped mycelial samples from the lamellae and found conidiophores and hyaline dry conidia (Fig. 2j-n) which suggested that the infestation was of the anamorphic genus Cladobotryum of the family of Hypocreaceae (Hypocreales, Sordariomycetes) of the Ascomycota (Cole and Kendrick 1971). Conidia were one to four-celled
(18.0\% one-celled, $63.9 \%$ two-celled, $9.8 \%$ three-celled; $8.2 \%$ four-celled; $\mathrm{n}=61$ ) with the majority being twocelled as it is typical for e.g. the mycopathogenic type species C. varium and C. mycophilum (Hughes 1958; Cole and Kendrick 1971; Rogerson and Samuels 1993; Back et al. 2012b; Tamm and Põldmaa 2013). Individual colonies were isolated from mycelium covering the 
stipe (strains AscoA1 and AscoB1) and from lamellae (AscoC1) of the infested mushroom.

Upon aging, degenerating mushrooms in the meadow were also visibly attacked by similarly sporulating fungi (not further shown). Another mycelial strain (AscoE1) was thus isolated on 11th of September 2015 from a heavily infested rotting stipe of a formerly healthy $A$. xanthodermus mushroom when it was found knockeddown in course of aging on the meadow.

Following some heavy rainfall on 14th and 15th of September 2015 with a drop in temperature from the $16-21{ }^{\circ} \mathrm{C}$ at previous days, a second flush of $A$. xanthodermus mushrooms was observed in the 3rd week of September 2015, at day temperatures (noon) of 12 to $19{ }^{\circ} \mathrm{C}$. Small spherical primordia were seen first on the 16th of September. Several structures were found 5 days later to be diseased at different developmental stages of mushroom development. Infestations started from white mycelial patches of several $\mathrm{cm}$ in diameter that developed first well visible on the 18th of September in the neighbourhoods on moss and decaying grass (Fig. 3), needles and cones (not shown). Sometimes these patches originated clearly from the remains of older mushrooms (Fig. 3f) but there were also multiple patches of fluffy white mycelium that did not obviously connect to a place of former mushroom production (Fig. 3n). Another fungal colony (strain AscoD1) was isolated from a decaying grass and moss sample from such a patch of sporulating white mycelium.

Mushrooms of differential developmental ages became infested by foreign mycelium, even very young primordia (Fig. 3a). Fluffy white mycelium grow onto the lower base of another young mushroom at the beginning of stipe outgrowth and, possibly as a consequence, the stipe of the young mushroom strongly bended with the mushroom cap laying down on the floor (Fig. 3a, b). Erect older drum-stick-like stages with extended stipes were also seen to be confined from the bases of the stipes (Fig. 3d-g). In some instances, heavy infestation lead to reddish-brown to lilac decolourisation of stipes (Fig. 3d, f) and also caps, and to collapse of the young mushrooms (Fig. 3f, g). Also older structures at and after cap opening were attacked by foreign mycelium (Fig. $3 \mathrm{~h}-\mathrm{m}$ ). Caps of attacked mushrooms turned brown to blackish-brown and shrivelled, thus quickly grew old (Fig. 3i, j; l, m) and rapidly rotted (not further shown). The reactions on older fruiting bodies appeared to be more aggressive and faster than reactions on younger stages.

\section{Mycopathogens in culture}

All five isolated strains formed conidiogenous mycelium and grew well on MEA at RT (about $22^{\circ} \mathrm{C}$ ) with increases in colony radii of $3.7 \pm 0.2,3.8 \pm 0.3,3.6 \pm 0.1$, and $3.6 \pm 0.1 \mathrm{~mm} /$ day (AscoA1, AscoB1, AscoC1, AscoE1) and of $2.4 \pm 0.1 \mathrm{~mm} /$ day (AscoD1), respectively. On the nutrient-rich YMG/T, the colonies increased in radius by $4.3 \pm 0.1,4.3 \pm 0.1,4.2 \pm 0.2$, and $4.4 \pm 0.1 \mathrm{~mm} /$ day (AscoA1, AscoB1, AscoC1, AscoE1) and $2.0 \pm 0.1 \mathrm{~mm} /$ day (AscoD1). The odour of the fungi when grown on MEA was pleasant faint sweet aromatic (camphor-like, resembling Eucalyptus smell). During growth phases on YMG/T, the odour was also first pleasant faint aromatic to medicine-like but when cultures on YMG/T aged and turned wine-red it became unpleasant sharp. The mycelial scents became stronger on both media with an increase in growth temperature to $28^{\circ} \mathrm{C}$.

All five strains grow on MEA at RT as a first slightly pigmented mycelium. Growing colonies on MEA of four of the strains stained first light yellow, while cultures of strain AscoD1 were stronger yellow from the beginning. Comparably little aerial mycelium was produced by all strains resulting in overall flat colony appearances. Growing colonies had small white fringed borders due to the production of multiple conidiophores with white flocks of masses of dry hyaline conidia. Within 2 to 3 days upon production, conidia separated from conidiophores and fell in larger aggregates onto the surface of the yellowish colonies (Fig. 4a). Per fully grown MEA

\footnotetext{
(See figure on next page.)

Fig. 3 Mycoparasitic mycelium infested Agaricus xanthodermus mushrooms at different developmental stages in a larger disease outbreak in the 3rd week of September of 2015. a, b Foreign mycelium grew from surrounding moss to a primordium and the stipe base of a young mushroom at the stage of stipe elongation and cap growth. c $24 \mathrm{~h}$ later the stipe base was surrounded by a thick layer of foreign mycelium, the stipe and cap were enlarged but the cap laid down on the floor due to strong bending of the stipe. $\mathbf{d}-\mathbf{m}$ Strong white mycelium found at multiple places in the grass and moss served as infection source of $A$. xanthodermus. Bases of elongating stipes of growing drum-stick-like young mushrooms were covered by a layer of foreign mycelium $(\mathbf{d}, \mathbf{f})$ and the same structures $24 \mathrm{~h}$ later photographed from different angles $(\mathbf{e}, \mathbf{g})$. While the yet less infected structure with the foreign mycelium confined only to the stipe base was still erect (e), the heavily infected structure with foreign mycelium reaching up to the cap already collapsed $(\mathbf{g})$. Infested young mushrooms at the start of partial veil rupture (h, i). $24 \mathrm{~h}$ later, the cap of the mushroom shown in $\mathbf{i}$ coloured brownish and the rupture of the partial veil blocked. Thick white patches of the pathogen were obvious on the cap surface (see arrow; $\mathbf{j}$ ). Also young stages of opened caps (the arrows mark the skirt-like annulus injured by the infestation) were attacked by mycelium growing upwards the stipe $(\mathbf{k})$ and eventually also onto the lamellae $(\mathbf{I}, \mathbf{m})$. Rapid decolourization and mushroom collapse within $24 \mathrm{~h}$ resulted from strong pathogen infestation $(\mathbf{I}, \mathbf{m})$. Strong white mycelium found at multiple places in the grass and moss $(\mathbf{n})$
} 

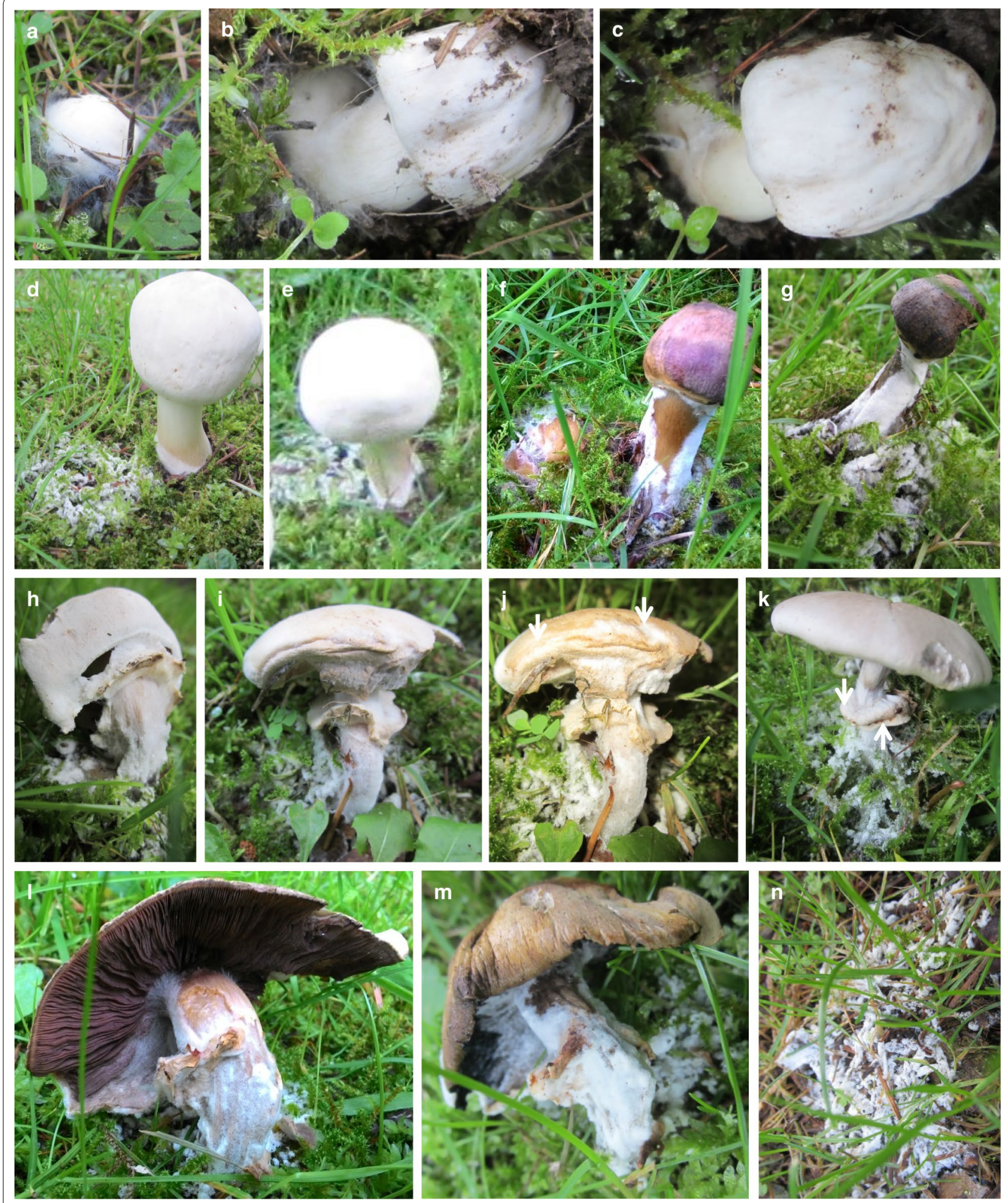


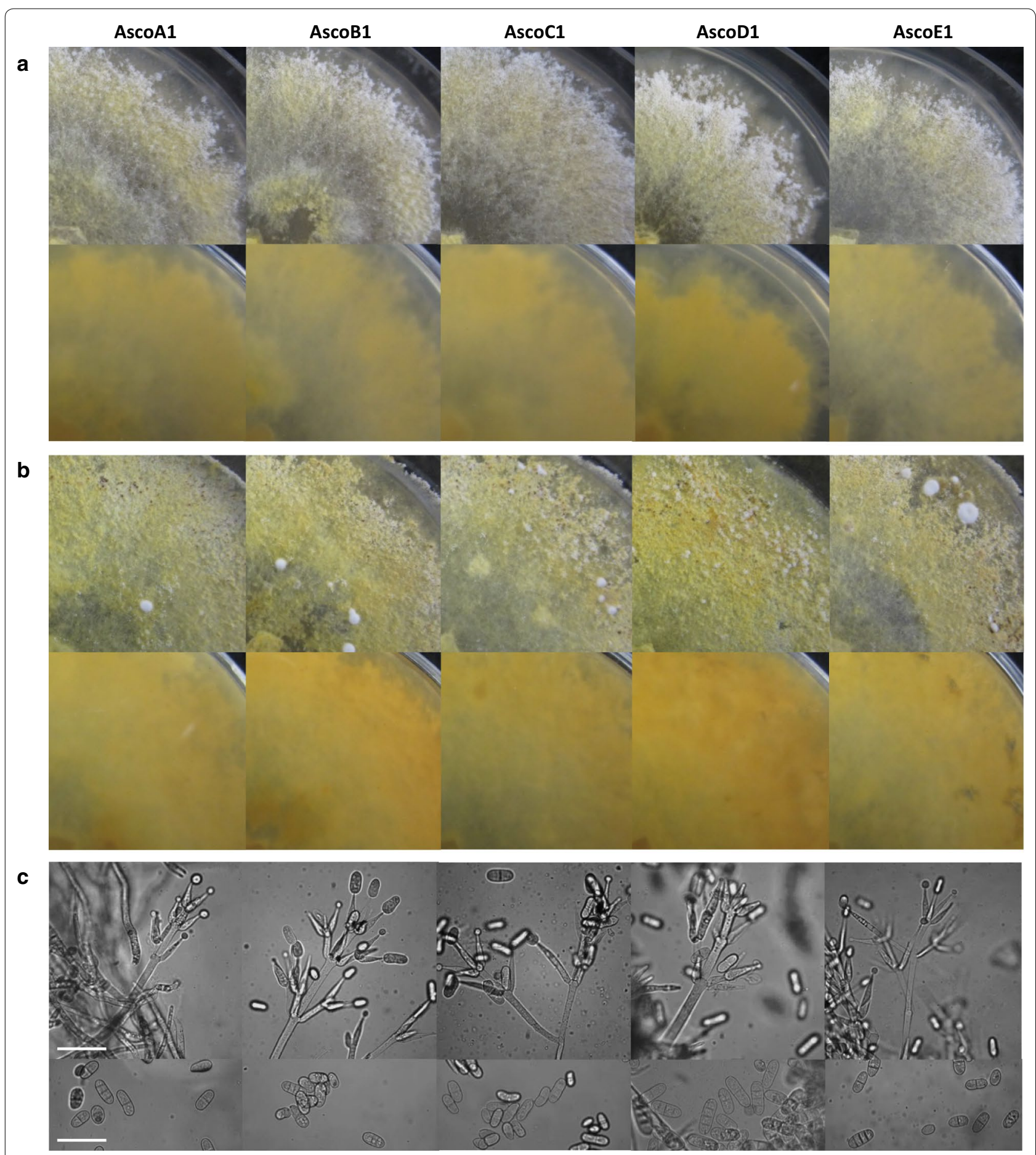

Fig. 4 Colony growth of five isolated conidiogenous strains on MEA at RT. a After 3-4 days of incubation with white fringed colony borders (upper row: plates from top, lower row: from reverse) and $\mathbf{b}$ with white pulvinate stroma in fully grown cultures after 25 days of incubation at RT (upper row: plates from top, lower row: from reverse). c Morphologies of conidiophores (top) and conidia (bottom) taken from aerial mycelium of growing cultures of isolated Hypomyces odoratus strains. Size bars: $50 \mu \mathrm{m}$ 
Table 1 Features of conidiophores of the five isolated strains grown at RT

\begin{tabular}{|c|c|c|c|c|c|c|}
\hline Cells & Parameter & AscoA1 & AscoB1 & AscoC1 & AscoD1 & AscoE1 \\
\hline \multirow[t]{15}{*}{ Conidiophores } & Stem & & & & & \\
\hline & 1st order whorls & $2-5$ & $2-4$ & $2-4$ & $2-4$ & $2-3$ \\
\hline & Whorls with branches & $0-3$ & $1-3$ & $0-3$ & $1-3$ & $0-3$ \\
\hline & Branches per whorl & $0-3$ & $1-3$ & $0-3$ & $1-3$ & $0-3$ \\
\hline & 1st order branches & $0-7$ & $1-4$ & $0-3$ & $1-3$ & $1-3$ \\
\hline & 1st order branch & & & & & \\
\hline & 2nd order whorls & $0-4$ & $0-3$ & $0-2$ & $0-3$ & $0-3$ \\
\hline & Whorls with branches & $0-2$ & $0-1$ & $0-1$ & $0-1$ & $0-1$ \\
\hline & Branches per whorl & $0-1$ & $0-1$ & $0-1$ & $0-1$ & $0-1$ \\
\hline & 2nd order branches & 2 & 1 & 1 & 1 & 1 \\
\hline & 2nd order branch & & & & & \\
\hline & Whorls & 2 & 1 & 1 & 1 & 1 \\
\hline & Branches total & $0-4$ & $0-3$ & $0-2$ & $0-3$ & $0-2$ \\
\hline & Whorls total & $3-7$ & $1-4$ & $1-5$ & $1-4$ & $1-4$ \\
\hline & $\mathrm{n}$ & 15 & 9 & 8 & 14 & 7 \\
\hline \multirow[t]{7}{*}{ Ampulliform phialides } & Per whorl without branches & $2-5$ & $2-5$ & $2-5$ & $2-5$ & $2-5$ \\
\hline & Per whorl with branches & $2-4$ & $2-3$ & $1-3$ & $1-2$ & $1-2$ \\
\hline & Length $(\mu \mathrm{m})$ & $35.8 \pm 7.7$ & $35.7 \pm 7.4$ & $38.1 \pm 8.3$ & $31.6 \pm 5.8$ & $32.9 \pm 5.7$ \\
\hline & Apex width $(\mu \mathrm{m})$ & $2.7 \pm 0.4$ & $3.3 \pm 0.6$ & $3.4 \pm 0.5$ & $3.8 \pm 0.6$ & $3.1 \pm 0.5$ \\
\hline & Width broadest point $(\mu \mathrm{m})$ & $8.1 \pm 1.1$ & $8.3 \pm 1.4$ & $8.1 \pm 0.8$ & $8.7 \pm 1.2$ & $8.3 \pm 1.2$ \\
\hline & Base width $(\mu \mathrm{m})$ & $5.2 \pm 1.0$ & $4.4 \pm 0.7$ & $5.0 \pm 1.0$ & $4.6 \pm 1.1$ & $4.6 \pm 0.9$ \\
\hline & $\mathrm{n}$ & 27 & 24 & 16 & 20 & 27 \\
\hline \multirow[t]{24}{*}{ Conidia } & No septum & & & & & \\
\hline & Length $(\mu \mathrm{m})$ & $15.3 \pm 1.2$ & $15.1 \pm 1.4$ & $15.5 \pm 1.8$ & $15.4 \pm 1.6$ & $16.2 \pm 1.0$ \\
\hline & Width $(\mu \mathrm{m})$ & $10.7 \pm 1.3$ & $10.3 \pm 1.3$ & $9.6 \pm 1.4$ & $10.0 \pm 1.0$ & $11.0 \pm 1.3$ \\
\hline & $\mathrm{n}$ & 21 & 13 & 16 & 15 & 13 \\
\hline & $\%$ of total & 20.0 & 14.8 & 14.4 & 14.9 & 13.1 \\
\hline & One septum & & & & & \\
\hline & Length $(\mu \mathrm{m})$ & $20.5 \pm 3.0$ & $20.7 \pm 3.1$ & $21.2 \pm 3.3$ & $21.1 \pm 4.8$ & $20.8 \pm 3.0$ \\
\hline & Width $(\mu \mathrm{m})$ & $10.8 \pm 1.2$ & $10.3 \pm 1.2$ & $10.0 \pm 1.3$ & $10.7 \pm 1.2$ & $10.4 \pm 1.2$ \\
\hline & $\mathrm{n}$ & 71 & 64 & 67 & 64 & 68 \\
\hline & $\%$ of total & 67.6 & 72.7 & 60.4 & 63.4 & 68.7 \\
\hline & Two septa & & & & & \\
\hline & Length $(\mu \mathrm{m})$ & $24.7 \pm 3.8$ & $23.4 \pm 1.5$ & $24.4 \pm 3.7$ & $26.2 \pm 4.4$ & $24.3 \pm 2.3$ \\
\hline & Width $(\mu \mathrm{m})$ & $11.2 \pm 1.4$ & $10.5 \pm 0.7$ & $10.3 \pm 0.9$ & $11.4 \pm 1.3$ & $11.2 \pm 1.3$ \\
\hline & $\mathrm{n}$ & 12 & 9 & 17 & 16 & 16 \\
\hline & $\%$ of total & 11.4 & 10.2 & 15.3 & 15.8 & 16.2 \\
\hline & Three septa & & & & & \\
\hline & Length $(\mu \mathrm{m})$ & 26.4 & $25.3 \pm 1.4$ & $31.7 \pm 3.3$ & $30.9 \pm 4.8$ & $26.6 \pm 0.1$ \\
\hline & Width $(\mu \mathrm{m})$ & 11.9 & $11.1 \pm 0.3$ & $10.5 \pm 0.5$ & $12.7 \pm 1.3$ & $12.8 \pm 1.0$ \\
\hline & $\mathrm{n}$ & 1 & 2 & 11 & 6 & 2 \\
\hline & $\%$ of total & 1.0 & 2.3 & 9.9 & 5.9 & 2.0 \\
\hline & All & & & & & \\
\hline & Length $(\mu \mathrm{m})$ & $20.0 \pm 4.0$ & $20.2 \pm 3.6$ & $22.0 \pm 5.2$ & $21.7 \pm 5.8$ & $20.9 \pm 3.5$ \\
\hline & Width $(\mu \mathrm{m})$ & $10.8 \pm 1.2$ & $10.3 \pm 1.2$ & $10.0 \pm 1.2$ & $10.8 \pm 1.3$ & $10.7 \pm 1.3$ \\
\hline & $n$ & 105 & 88 & 111 & 101 & 99 \\
\hline \multirow[t]{2}{*}{ Conidia per plate } & MEA & $4.4 \pm 1.2 \times 10^{7}$ & $8.3 \pm 4.9 \times 10^{7}$ & $7.9 \pm 2.5 \times 10^{7}$ & $1.8 \pm 1.4 \times 10^{7}$ & $4.4 \pm 1.7 \times 10^{7}$ \\
\hline & $\mathrm{YMG} / \mathrm{T}$ & $1.2 \pm 0.6 \times 10^{8}$ & $1.2 \pm 0.2 \times 10^{8}$ & $9.2 \pm 1.3 \times 10^{7}$ & $2.3 \pm 0.1 \times 10^{7}$ & $9.9 \pm 3.9 \times 10^{7}$ \\
\hline
\end{tabular}

Strains were cultivated for 13 days at RT on MEA and conidiophores were taken for microscopy from the outer white growth zone characterized by flocks of conidia. $\mathrm{n}=$ number of structures or cells analyzed. For counting spores per plate, five plates per strains and per medium were inoculated and spores were counted after fully growth of plates at RT 
plate, the strains produced between $2 \times 10^{7}$ and $8 \times 10^{7}$ hyaline 0 - to 3 -septate conidia (Table 1 ). With time, fully grown colonies turned from slighter yellow to dark yellow (after 4 to 6 days of growth at RT to after about 14 days; when cultured at $28{ }^{\circ} \mathrm{C}$, these processes were 1 to 3 days faster) while strain AscoD1 was still darker pigmented as compared to the others. Cultures appeared to be in a final stage at RT after about 25 days of incubation, for the appearance of mycelium and colony color. The observations on plates cultivated at RT usually lasted up to 36 days as the plates became drier. Mainly the mycelium but also the agar was stained by the strains by yellow pigments. In one experiment when plates were kept for 2 months in very humid conditions, some plates of strains AscoB1 and AscoD1 adopted in the end a mixed yellowslightly pinkish pigmentation while none of the other strains did change the color. Further in aging MEA cultures after around 3 weeks of incubation, all five strains started to produce hard white patches of dense mycelial pulvinate stroma which increased in numbers with time (between dozens to $>100$ per plate). First they were small, less than $0.1 \mathrm{~mm}$ in $\varnothing$, but with time they could grow to patches of up to 3-4 mm in $\varnothing$ (Fig. 4b). After around 30 days of cultivation with drying out medium, round dark brown microsclerotia (AscoA1: $0.33 \pm 0.08 \mathrm{~mm}$ in $\varnothing, \mathrm{n}=16$; AscoB1: $0.37 \pm 0.08 \mathrm{~mm}$ in $\varnothing, \mathrm{n}=13$; AscoC1: $0.35 \pm 0.08 \mathrm{~mm}$ in $\varnothing, \mathrm{n}=14$; AscoD1: $0.36 \pm 0.07 \mathrm{~mm}$ in $\varnothing, \mathrm{n}=17$; AscoE1: $0.36 \pm 0.07 \mathrm{~mm}$ in $\varnothing, \mathrm{n}=15$ ) filled with large round unstained cells formed in aging colonies (not shown). In addition, masses of round chlamydospores (AscoA1: $13.3 \pm 1.7 \mu \mathrm{m}$ in $\varnothing, \mathrm{n}=22$; AscoB1:
$13.5 \pm 1.7 \mu \mathrm{m}$ in $\varnothing, \mathrm{n}=26 ;$ AscoC1: $13.9 \pm 1.6 \mu \mathrm{m}$ in $\varnothing, \mathrm{n}=28$; AscoD1: $13.5 \pm 2.2 \mu \mathrm{m}$ in $\varnothing, \mathrm{n}=22$; AscoE1: $13.9 \pm 1.2 \mu \mathrm{m}$ in $\varnothing, \mathrm{n}=24$ ) arose in chains from swelling and fragmenting of vegetative hyphal cells (not shown).

Mycelia of all five strains on YMG/T medium were first nearly unpigmented during the fresh growth at RT. The cultures were characterized by loose white fluffy aerial mycelium starting to regularly develop behind the colony growth fronts on the 1-day-old mycelium and to produce conidia over the following days. Spreading in the growing colony outwards from the inoculum, substrate mycelium with the agar began to stain yellowish 1 to 2 days after first aerial mycelium production (at $28{ }^{\circ} \mathrm{C} 1$ or 2 days earlier than at RT), while the yellow colour intensified continuously with further mycelial age in growing. The yellow colour increased in intensity during the further incubation also after plates were fully grown (after 5 and in the case of AscoD1 7 days of incubation) while after about 15 and, in the case of AscoD1, 20 days there was a switch in colour to first light pinkish and later wine-red (Fig. 5). The final cultural stages also appeared to have been reached on YMG/T plates after culturing at RT for about 25 days, followed by only desiccation reactions with continued incubation up to 36 days.

Pink to red medium coloration has been reported before e.g. from older PDA cultures of Hypomyces/Cladobotryum strains (Back et al. 2010; Carrasco et al. 2016; Muhammad et al. 2019). Hypomyces/Cladobotryum species are known to produce aurofusarin as pigment (Rogerson and Samuels 1989; Põldmaa 2011; Tamm and Põldmaa 2013; Carrasco et al.

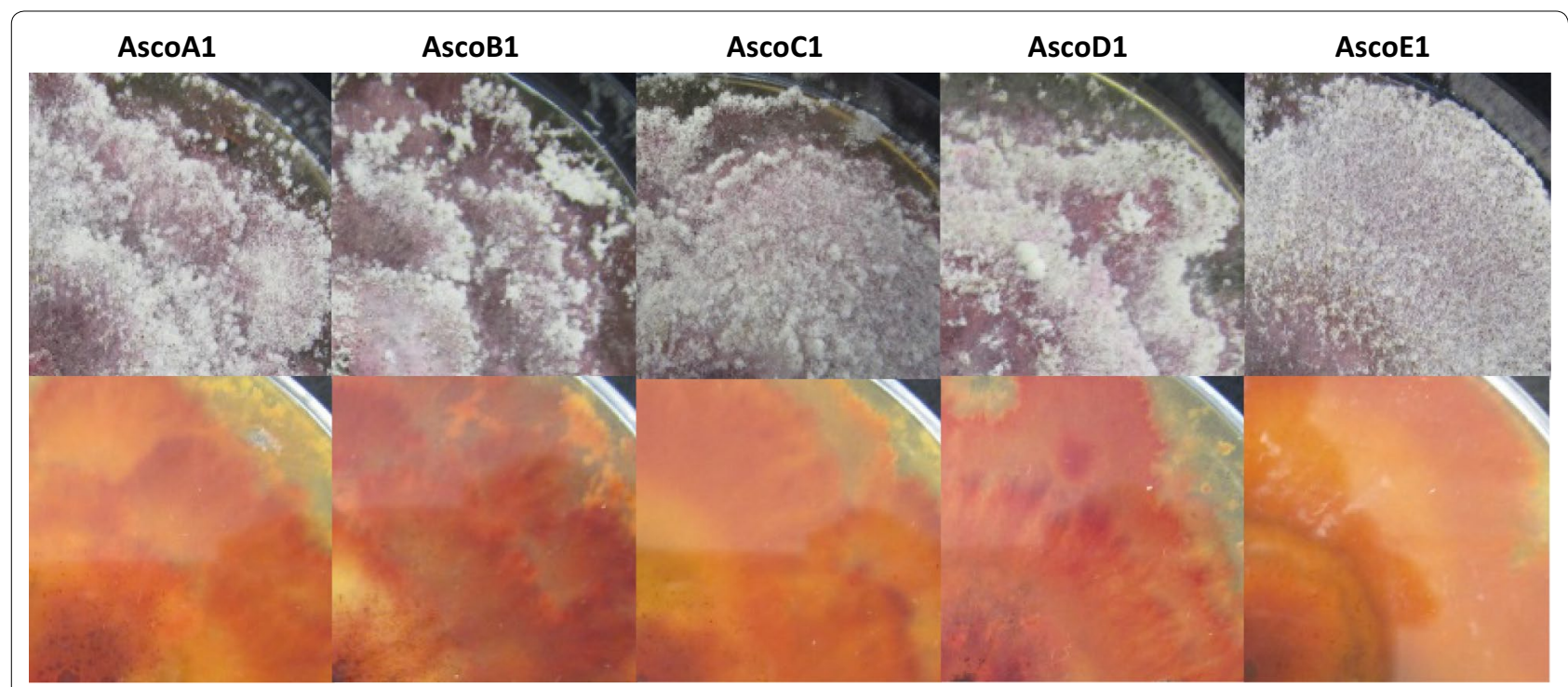

Fig. 5 Colony morphology of five isolated conidiogenous strains on YMG/T at RT after 25 days of incubation. Upper row: plates from top, lower row: reverse 
2016) which changes in color from yellow to red depending on the $\mathrm{pH}$ (Ashley et al. 1937). We therefore checked the $\mathrm{pH}$ in the medium over the time of cultivation. When colonies on YMG/T plates were stained yellowish to dark yellow, the $\mathrm{pH}$ in the medium did not much change and was around 5.5 to 6 . With onset of pinkish coloration however, the $\mathrm{pH}$ increased to values of 6.5 to 7. With increasing colorization when the cultures turned pink to finally wine-red, the $\mathrm{pH}$ rendered into the alkaline range to values of around 7 to 7.5 and then to 7.5 to 8 . For comparison, the $\mathrm{pH}$ in the MEA cultures was in the acidic range with $\mathrm{pH} 4.5$ in slightly yellow cultures and $\mathrm{pH} 4$ and sometimes even $\mathrm{pH} 3$ in dark yellow cultures. In 1-month-old cultures of the stronger yellow cultures of strain AscoD1, the $\mathrm{pH}$ raised first slightly to $\mathrm{pH}$ 5. In 2-month-old plates of strain AscoD1 and also of strain AscoB1, within a few days under color changes to mixed yellow-pinkish and then yellowish-pink, the $\mathrm{pH}$ raised further to 6 to 6.5 and then $\mathrm{pH}$ 7. Cultures of strains AscoE1, AscoA1, and finally AscoC1 also increased in $\mathrm{pH}$ to 6 but two to several days later, along with color changes into yellow-pinkish.

The pigments in YMG/T cultures stained majorly the submerged mycelial agar layer and to less part the agar beneath. Notably, the colony surfaces remained white in appearance due to the considerable amounts of whitish aerial mycelium with huge amounts of hyaline conidia produced (for spore numbers per fully grown plates see Table 1). The dry conidia assembled into larger flocks on the tips of the conidiophores. During colony growth, thick aerial mycelium arose as high as up to the lids of the Petri dishes, transferring large parts of the clumps of spores onto the plastic surface (not shown). This thick aerial mycelium was longer lasting. After mycelial growth on a plate was completed, and after the change in colour of the substrate mycelium with agar from yellow to wine-red and along with the evaporation of any humidity from the lids of the Petri dishes (after about 25 days of incubation), the aerial mycelium in undisturbed plates collapsed slowly throughout the colony. With opening the lid however, the aerial mycelium collapsed immediately. Eventually, the aggregated conidial clusters fall down from aerial mycelium and lids of Petri dishes in irregular patterns onto the surfaces of the colonies. Spore aggregates collected from agar and from lids of Petri dishes needed harsh forces to separate them into individual cells for counting (Table 1). Furthermore, all strains produced on YMG/T on the surfaces of aging cultures (after about 30 days of cultivation, mainly in the outer regions of colonies) also masses of dark brown microsclerotia which were much more in numbers but of similar sizes than those on MEA (AscoA1: $0.40 \pm 0.08 \mathrm{~mm}$ in $\varnothing$, $\mathrm{n}=15$; AscoB1: $0.39 \pm 0.05 \mathrm{~mm}$ in $\varnothing, \mathrm{n}=20$; AscoC1:
$0.37 \pm 0.05 \mathrm{~mm}$ in $\varnothing, \mathrm{n}=16$; AscoD1: $0.35 \pm 0.03 \mathrm{~mm}$ in $\varnothing, \mathrm{n}=20$; AscoE1: $0.32 \pm 0.03 \mathrm{~mm}$ in $\varnothing, \mathrm{n}=22$ ). Aging cultures on YMG/T did not produce white stromas but they gave rise to some chlamydospores resulting in chains from swellings and fragmenting of hyphal cells (AscoA1: $13.3 \pm 1.4 \mu \mathrm{m}$ in $\varnothing, \mathrm{n}=22$; AscoB1: $13.5 \pm 1.5 \mu \mathrm{m}$ in $\varnothing$, $\mathrm{n}=21$; AscoC1: $13.2 \pm 1.8 \mu \mathrm{m}$ in $\varnothing, \mathrm{n}=20$; AscoD1: $12.9 \pm 1.6 \mu \mathrm{m}$ in $\varnothing, \mathrm{n}=24$; AscoE1: $13.4 \pm 1.7 \mu \mathrm{m}$ in $\varnothing$, $\mathrm{n}=23)$.

\section{Species identification}

Conidiophores with conidia were analyzed in more detail from the strains grown on MEA (Table 1). Conidiophores with conidia on mycelia of all five strains were verticillate as typical for the Hypomyces/Cladobotryum genus. Conidiophores were separated over their length into several cells. They had stems with 2 to 5 whorls with up to 5 phialides each and they were usually irregularly branched, with 1st order sidebranches arising in numbers between 1 and 3 among some phialides at the lower whorls of the stem and with some 2nd order sidebranches arising at the lower whorls of 1st order sidebranches (Fig. 4c; Table 1). The up to 5 phialides per whorl were successively produced (Fig. 4c and see also Fig. 2 j-n) and grew into lengths of $>30 \mu \mathrm{m}$ (Table 1). The ampulliform phialides tapered from broader regions (width $>8 \mu \mathrm{m}$ ) shortly above their bases (width ca. $5 \mu \mathrm{m}$ ) to slim blunt apexes of widths of around $3 \mu \mathrm{m}$. Conidiospores were produced at the simple tips of the ampulliform phialides in monoblastic mode (Fig. 4). First, the young blastospores were equally swelling but with increase in size, they often buckled with further growth to the lateral side (Fig. 4c and see also Fig. 2 j-n). Released conidia were hyaline, oblong in shape with rounded edges, had sometimes visibly a hilum at the basal ends and different numbers of septa (Fig. 4c). The majority of conidia of all strains (60-72\%) were two-celled. However, strain AscoA1 had more non-septated spores (20\%, comparably to the mycelium grown on the infected cap from which AscoA1 was isolated, please see above) than the other strains. Strains AscoC1, AscoD1 and AscoE1 had higher numbers of spores with two or also three septa (in sum 18.2 to $25.2 \%$; Table 1). Between the strains, there were some measured minor size variations of the spores (Table 1). Spore lengths ranged from 13.2 to $33.0 \mu \mathrm{m}$ (AscoA1), 13.4 to $28.8 \mu \mathrm{m}$ (AscoB1), 11.7 to $36.5 \mu \mathrm{m}$ (AscoC1) and 13.6 to $37.4 \mu \mathrm{m}$ (AscoD1), 13.8 to $28.2 \mu \mathrm{m}$ (AscoE1). In tendency, spore lengths and widths increased with numbers of septa (Table 1). The strains AscoC1 and AscoD1 with higher percentages of both 3- and 4-celled spores had thus a bit more of the longer spores as compared to the other three strains. 
The general morphological parameters of conidiophores and conidia of the five strains matched descriptions of $\mathrm{H}$. odoratus/C. mycophilum in the literature (Arnold 1963; Gams and Hoozemans 1970; Cole and Kendrick 1971; Gray and Morgan-Jones 1980; Back et al. 2012b; Tamm and Põldmaa 2013; Gea et al. 2014). The occurrence of microsclerotia and presence of round chlamydospores in the aged mycelium and yellow to red stained colonies with a strong smell on nutrientrich YMG/T medium also concur with descriptions of H. odoratus/C. mycophilum (Helfer 1991; McKay et al. 1999; Grogan 2006; Gea et al. 2014; Carrasco et al. 2017). In other instances reported in the literature, no peculiar stronger smell was noted by isolates of $H$. odoratus (McKay et al. 1999; Gea et al. 2019), similar as in this study when growing the five strains on MEA plates.

We amplified and sequenced the $530 \mathrm{bp}$ long ITS rDNA regions of all five isolates (KX098646-KX098650). The sequences of the strains are identical to each other and $99-100 \%$ identical to the ITS sequences of $H$. odoratus (FN859435; Põldmaa 2011) and C. mycophilum strains (JF693809, JF505112, AB527074, JQ004737, Y17094, Y17095, KP267826) shown to infect mushrooms in culture (McKay et al. 1999; Back et al. 2010; Kim et al. 2012; Carrasco et al. 2016; Gea et al. 2016). In contrast, they were only $98 \%$ identical to $H$. rosellus (FN859440, FN859442; Põldmaa 2011) and C. dendroides ITS sequences (Y17090, Y17092; McKay et al. 1999). Three subgroups of ITS fragments of $H$. odoratus/C. mycophilum strains are distinguished (McKay et al. 1999; Tamm and Põldmaa 2013; Gea et al. 2016) by a 1 base pair difference in the ITS1 sequence (base A at position 80 in subgroup $1 / 2$ versus $G$ in subgroup 3 ) and 1 or 2 base pair differences in the ITS2 region (base $\mathrm{T}$ at position 390 in subgroup $1 / 2$ versus $C$ in subgroup 3 ; base $C$ at position 507 in subgroup 1 versus $\mathrm{T}$ in subgroups $2 / 3$ ). Our sequences fall into $H$. odoratus/C. mycophilum subgroup 3 together with strains from Ireland, Estonia, Russia and the USA (McKay et al. 1999; Tamm and Põldmaa 2013).

\section{Fruiting body infection tests}

All five isolated $H$. odoratus strains were tested on complete or halved commercial mushrooms of A. bisporus. All five strains regularly infected all commercial A. bisporus mushrooms, regardless of whether the inoculum was placed onto a non-injured stipe or cap or onto cuts of stipes and caps of sliced mushrooms (Fig. 6). After placing fresh mycelial MEA agar blocks of the ascomycetes onto a stipe or a cap region of $A$. bisporus, the hyphae started to grow (1st day). When intact pilei were inoculated, the surrounding $A$. bisporus cap region in consequence caved in with a growing pathogen, resulting in a visible dent with the inoculum in the center (2nd day). Later on, regardless of place of inoculation, the hyphae spread over all the mushrooms (3rd day) and produced huge white-coloured masses of conidia. During this time, the pathogens were very aggressive and appeared to absorb nutrients from the mushrooms, while the mushrooms reduced in sizes and weights, changed in color from white to light brownish, and became watery-rotten (5th to 6th day). All infectious strains, AscoA1 to AscoE1 gave rise to black microsclerotia on the overgrown surface of the A. bisporus samples (not further shown).

In contrast to fruiting bodies of $A$. bisporus, strains AscoA1, AscoB1 and AscoD1 did not grow much on commercial $P$. ostreatus fruiting bodies, neither when inoculated on the cap surface nor on the lamellae nor on the stipes. P. ostreatus thus showed resistance to the ascomycetes. At most, the $H$. odoratus hyphae spread

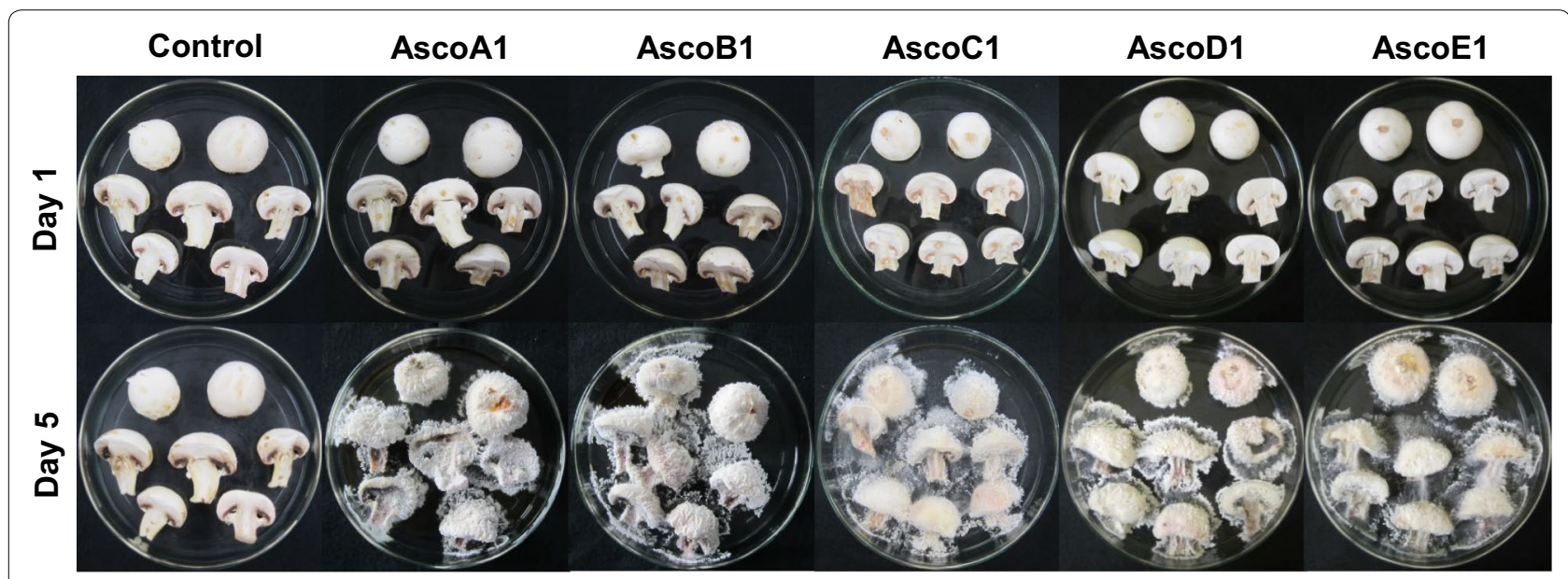

Fig. 6 Infection test with commercial A. bisporus fruiting bodies. Top row: day of inoculation, bottom: mushrooms after 5 days of cultivation at RT 
from the inocula only over very small areas of the mushrooms without obvious symptoms of disease but not over the complete mushrooms. Importantly, when placing a mycelial agar block at the centre of mushroom caps, the H. odoratus mycelia started to grow out more likely on the side of the agar blocks towards the stipe region than upwards of the cap region. Only strains AscoC1 and AscoE1 showed in exceptional cases some infection by mycelial growth on the base of $P$. ostreatus stipes (noticed on each 2 of 25 in total tested fruiting bodies; Fig. 7). Still, also in these rare cases the

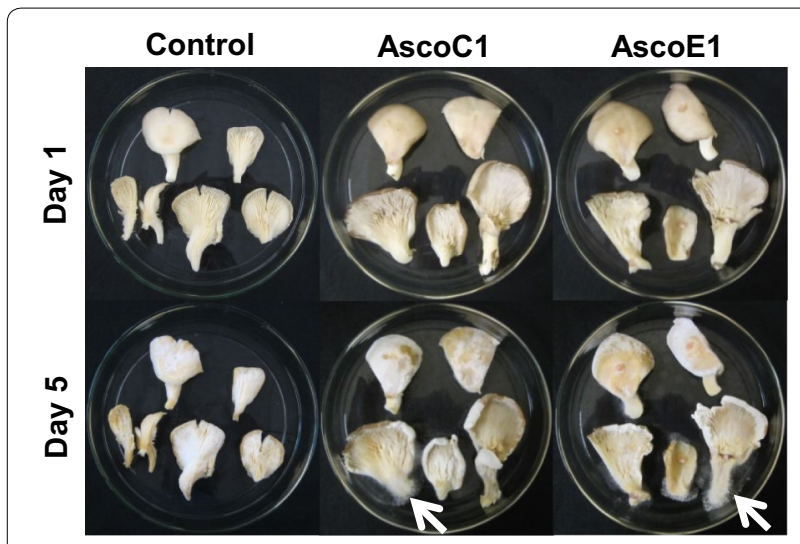

Fig. 7 Infection test with commercial P. ostreatus fruiting bodies. Top: day of inoculation, bottom: mushrooms after 5 days of cultivation at RT. Arrows mark infested stipe regions. Other mycelial outgrowth noticed came from $P$. ostreatus aggressiveness towards $P$. ostreatus was comparatively low with few amounts of conidia formed by the growing mycelium. As a further interesting observation, $P$. ostreatus tissue growth (growing hyphae had clamps) occurred at the stipe margins, cap margins and the lamellae of inoculated mushrooms and also of uninfected controls. Such growth probably strengthened the mushrooms and helped in resistance against the ascomycetes.

We also tested in similar manner A. xanthodermus mushrooms collected from the wild (KX098653) with H. odoratus strains AscoA1, AscoB1 and AscoC1. Young mushrooms with still closed caps were infected by agar pieces with the ascomycetes positioned either at the stipes or the caps. Within 6 days at RT, mycelium from the inocula of the stipes grow onto the darkened gills of the matured mushrooms while stipes with the annuli degenerated whereas the caps still remained in good shape (Fig. 8). In contrast upon inoculation of pilei, tissues overgrown by the pathogens shrivelled under appearance of liquid yellow-brown droplets on the cap surface and the caps degenerated quickly (not shown). Similar observations were made, when $A$. arvensis mushrooms from the wild (KX098654) were inoculated with strain AscoC1 (not further shown).

\section{Infection tests of growing mycelial cultures}

The infection potential of the five mycopathogenic strains was further tested against mycelial cultures of $A$. xanthodermus, $P$. ostreatus and C. cinerea, respectively. For

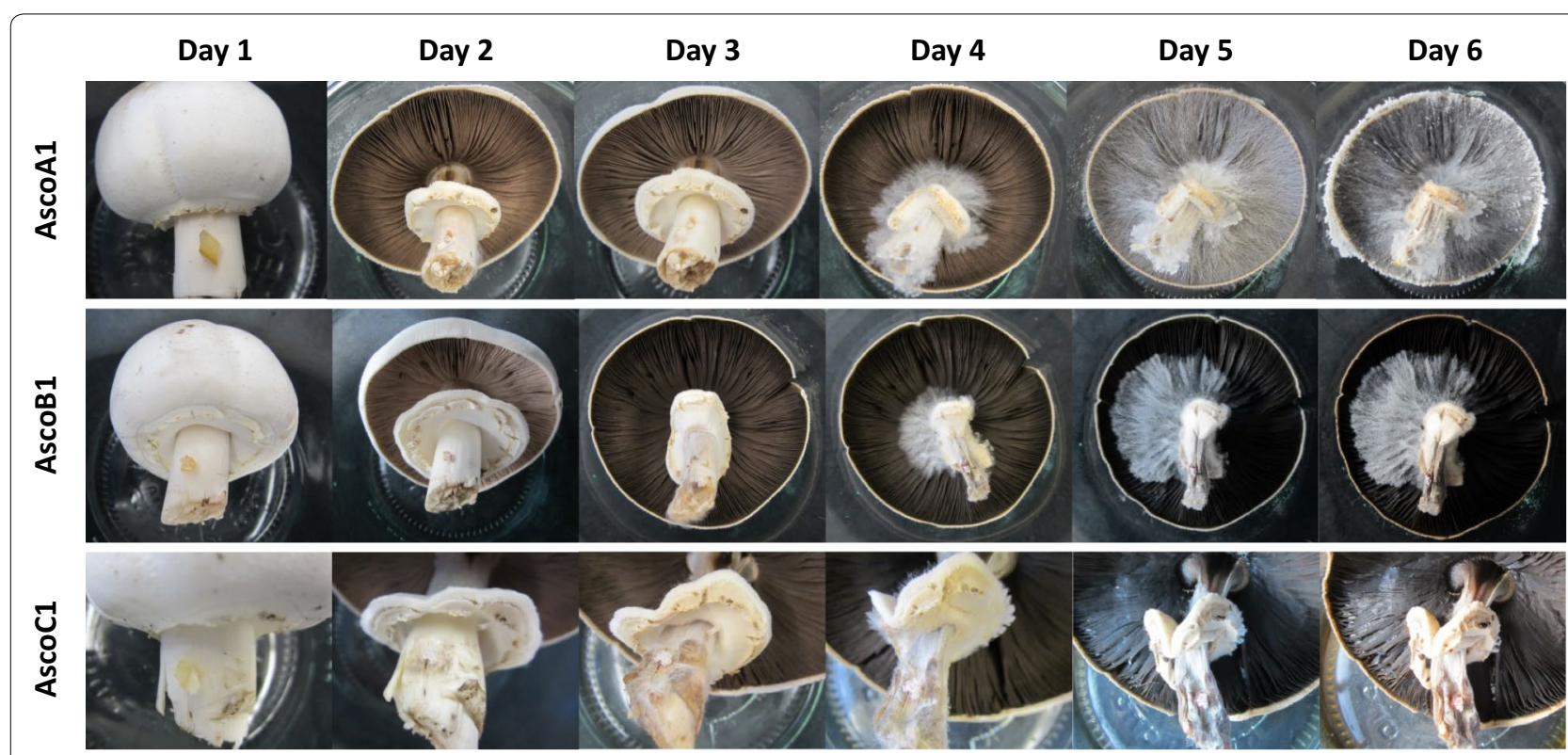

Fig. 8 Young A. xanthodermus fruiting bodies inoculated with H. odoratus strains. Upon stipe inoculation of mushrooms kept within sterile glass jars, the progress in mushroom development and pathogen infestation at RT was photographed once per day 

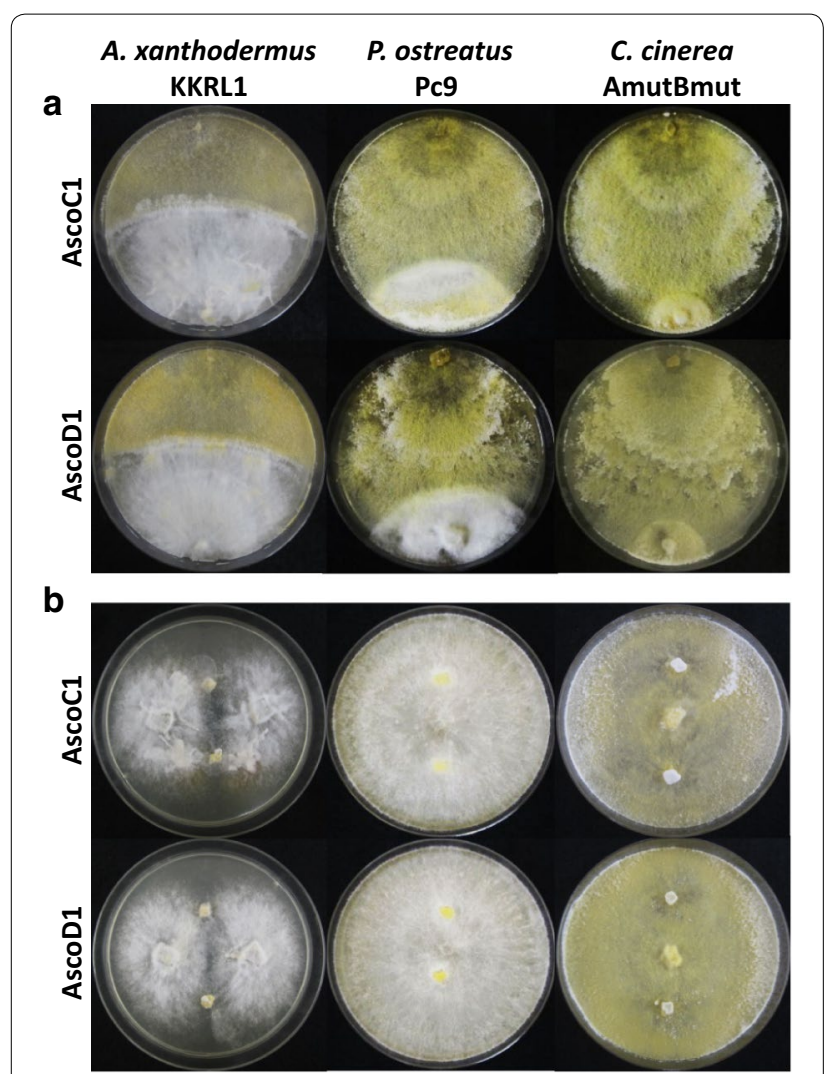

Fig. 9 Mycelial growth confrontation tests (top rows) and grown mycelium challenge tests (bottom rows) of $A$. xanthodermus KKRL1, P. ostreatus Pc9 and C. cinerea AmutBmut by $\mathrm{H}$. odoratus isolates on MEA, photographed after 20 days of incubation at RT after inoculation of the pathogen

mycelial confrontation tests, we inoculated mycelial agar plugs from a test fungus and a respective mycopathogen onto MEA plates at opposite edges of Petri dishes (Fig. 9a).

The dikaryotic A. xanthodermus isolate KKLR1 grew slowly on MEA at RT (about $1.4 \pm 0.1 \mathrm{~mm} /$ day) with a flat cottony-dense white-colored mycelium growing in a loosely organized dense fan-strand pattern. Therefore for the mycelial confrontation tests, the species was inoculated at the edges of Petri plates and cultivated 15 days prior to the inoculation of the mycopathogens at the edges of the opposite side of the plates (see examples of AscoC1 and AscoD1 confrontation tests in Fig. 9a). Once the mycelial growth fronts of the two species reached each other in further incubation (after about 12 to 18 days of incubation), both $H$. odoratus as $A$. xanthodermus colonies were stopped in further growth at the confrontation zones with some combat reactions at the colony borders. The flat dense white mycelium of $A$. xanthodermus showed some resistance against overgrowth by the mycopathogens. However, bunches of sporulating
$H$. odoratus aerial hyphae were observed to grow over the A. xanthodermus colonies. The mycopathogens produced huge amounts of dry aerial conidia which landed in clumps also on $A$. xanthodermus mycelium but without recognisable germination. Unevenly distributed, ribbon or thread-like mycelial aggregates appeared as deformations in the A. xanthodermus colonies (Fig. 9a) and, with longer incubation time, on their surfaces also faint zones of yellowish-stained aerial $H$. odoratus mycelium overlaying the basidiomycete. Further in older cultures, $A$. xanthodermus appeared to produce a new thicker white aerial mycelium at the colony borderlines which grow a few $\mathrm{mm}$ to over $1 \mathrm{~cm}$ into the zones of the opponent colonies and covered the edges of the $H$. odoratus colonies (Fig. 9a). A. xanthodermus in single culture on MEA plates rarely produced clamp cells at its hyphae. However, some clamp cells were also observed on growth fronts of the new white mycelium overgrowing the $H$. odoratus mycelium, supporting that the basidiomycete survived and revived in the dual cultures.

Observation with $A$. xanthodermus strain KKRL1 on YMG/T plates were in parts similar. A. xanthodermus colonies were for 4 weeks pregrown into colonies of ca. 3 to $3.5 \mathrm{~cm}$ in diameter prior to inoculation of the mycopathogens. The overgrowth of $A$. xanthodermus colonies by aerial mycelium of $H$. odoratus strains was then stronger with fast growing thick bunches of conidiogenous hyphae attracted to and overlaying densely the A. xanthodermus mycelium. Masses of white clumps of conidia were produced on the plate and fell over the covered $A$. xanthodermus mycelium. The areas on the plates with the grown $H$. odoratum colonies turned lilac-red unlike the unstained agar underneath the covered $A$. xanthodermus mycelium. On the reverse of the cultures, dense assemblies of many submerged brown microsclerotia filled with large round cells appeared underneath the overgrown A. xanthodermus colonies and often also underneath in the agar zone around the $H$. odoratum inocula. Microsclerotia were also observed above the overgrown A. xanthodermus mycelium. Mycelial samples from $A$. xanthodermus colonies overgrown by $H$. odoratus strains revealed under the microscope single-celled chlamydospores and many conidia of the ascomycete. No new outgrowth of mycelium was observed on plates from the $A$. xanthodermus colonies which might not have been strong enough for such activity if still alive.

In mycelial confrontation experiments with $P$. ostreatus monokaryon Pc9 on MEA, the mycopathogens grow also faster than strain Pc9 and the yellow stained colonies produced huge amounts of conidia (Fig. 9a). Where the growing species met, combat reactions resulted, leading to a margin of denser white mycelium formed by the Pc9 strain as delineation from the yellowish mycopathogens. 
However, very long conidiogenous hyphae of the mycopathogens loosely overgrow the $P$. ostreatus colonies and conidia were produced in small white flocks especially at the plastic edges of Petri dishes above the P. ostreatus colonies. With time, some mycelial patches above the Pc9 mycelium stained yellowish. In mycelial samples from the $P$. ostreatus colonies under the microscope, no or only few mostly two-celled conidia were detected. From the reverse of plates, sometimes thinner necrotic areas became visible in the unstained $P$. ostreatus colonies of older plates ( 1 month) while in other areas and cases the mycelium grew denser. In mycelial confrontation tests on YMG/T medium with much more production of aerial $H$. odoratus mycelium, reactions were much stronger. Conidiogenous hyphae were strongly attracted in growth to the Pc9 colonies for covering the colonies, and masses of conidia in many very large aggregates were produced above the $P$. ostreatus mycelium. On the reverse side of cultures, production of some brown microsclerotia were observed underneath in the unstained $P$. ostreatus colonies, while all other parts of the medium covered with mycelium of $H$. odoratum strains were stained pink to lilac-red.

The third species tested, C. cinerea homokaryon AmutBmut, in contrast was not able on MEA to defeat any of the five mycopathogens in combat reactions. C. cinerea was easily overgrown by all five $H$. odoratum strains when the growing colonies were confronted with each other. $H$. odoratum strains formed regular yellow colonies with also regular conidia production over the whole plates including the growth zones of $C$. cinerea (Fig. 9a). Because $C$. cinerea AmutBmut is a self-compatible homokaryon by mutations in its mating type loci, it forms clamp cells at its hyphal septa (Swamy et al. 1984). In mycelial samples of overgrown $C$. cinerea colonies underneath the microscope, clamp cells at hyphal septa were only exceptionally seen, suggesting that at least parts of the existing mycelium probably came from the mycopathogens. White pulvinate stroma developed on top of the $C$. cinerea colonies in 1 month old MEA plates. In confrontation tests on YMG/T plates, $C$. cinerea colonies of equal growth age than the mycopathogens were also quickly overgrown by the $H$. odoratus strains through outgrowth of dense fast growing hyphal fans of $\mathrm{H}$. odoratus mycelium being attracted to the smaller $C$. cinerea colonies. Masses of conidia were produced on top of the C. cinerea colonies while the edges of the colonies were less sharp and, as seen on the reverse of the plates, the pink $H$. odoratus staining diffused into the borders of the $C$. cinerea areas. In confrontation tests with larger pregrown C. cinerea colonies (inoculated at edges of plates and incubated 4 days at $37{ }^{\circ} \mathrm{C}$ prior to inoculation of $H$. odoratus strains and transfer to RT), defense was stronger with sharper colony borders against the mycopathogens. However, the surfaces of the $C$. cinerea mycelia were also quickly covered by fast growing conidiophores and masses of conidia.

\section{Infection tests of grown mycelial cultures}

In other experimental series to challenge a grown test fungus, mycelial agar plugs of mycopathogens were placed at $2 \mathrm{~cm}$ distance from inocula on the top of the completely grown basidiomycete mycelium (Fig. 9b). In the grown mycelium challenge tests with already established mycelium (grown with two inocula per MEA plate for 20 days at RT), the mycelium of $A$. xanthodermus could well resist the five mycopathogens. In the basidiomycete colonies, some white thread- or ribbon-like or in addition also globular compact mycelial aggregates were detected as reactions (Fig. 9b), similar as before in the confrontations tests on the same medium. Clamp cells were detected in the mycelium. When using slowly growing A. xanthodermus colonies on YMG/T medium for surface inoculation with the $H$. odoratus strains, outgrowth of the mycopathogenic strains on the basidiomycetous colonies was impeded unlike on free agar surfaces.

In mycelial challenge tests, we also noticed on both media little or no outgrowth of mycopathogens when inoculated on the top of established Pc9 mycelium (Fig. 9b). Only sometimes in closer vicinity of the inocula of $H$. odoratus strains, zones of some denser mycelium or some minor necrotic reaction were observed. Like the fruiting bodies of the species, also the vegetative mycelium of $P$. ostreatus exerts thus some but not full resistance against the mycopathogens.

No much outgrowth of the mycopathogens was then observed when inoculated on YMG/T plates that were fully grown with dense $C$. cinerea mycelium (inoculated in the middle of plates and grown for 6 days at $37^{\circ} \mathrm{C}$ ). When inoculated on top of established but less dense C. cinerea mycelium on fully grown MEA plates, the $H$. odoratus strains however could easily overgrow the C. cinerea mycelium and surfaces of colonies stained yellowish by the presence of the mycopathogen (Fig. 9b). Necrotic areas became visible in the $C$. cinerea colonies underneath by thinned mycelium around the inocula of the mycopathogens in mycelial challenging tests on MEA (Fig. 9b).

\section{Discussion}

In this study, we report observations on mycoparasitic infections of $A$. xanthodermus mushrooms in nature. We have observed unimpeded developing mushrooms in years 2012 to 2017, variably in the months June, August, September and, in 2015, also in November, usually after comfortably warm weather conditions. Induction of 
fruiting body development of $A$. xanthodermus seems to need sufficient previous rainfall possibly to both, moisture the ground and create higher humidity in the air. Consequential to the rainfall, a drop in air temperature likely will also be favourable for induction of fruiting. Fruiting body development proceeds from ball-like primordia over drum-stick-shaped, still closed young mushrooms to mature mushrooms with open umbrellas and first pinkish and then brown lamella (Fig. 1). The speed of development from primordia to fruiting body maturation seems to depend also on the temperature and took in our observations between $10-13$ and 6-8 days at colder and warmer temperature (around $12-15{ }^{\circ} \mathrm{C}$ and $18-22{ }^{\circ} \mathrm{C}$ ), respectively. Mature fruiting bodies can last further 10 to 15 days.

\section{Infections of $A$. xanthodermus fruiting bodies by $H$. odoratus cobweb in nature}

Interestingly, in a first flush of mushrooms in early September 2015, one split fruiting body was visibly affected by a fungal infestation (Figs. 1e-1, 2). While we do not know whether this single mushroom was injured prior to infestation or whether infestation resulted in the injury, our observations from infections in the subsequent flush of mushrooms suggest that injury is not a premise of infection of the species in nature. Moreover, we observed that all stages of fruiting body development were susceptible for the mycopathogen (Fig. 3). The infections on $A$. xanthodermus were identified by morphological means (conidiophores and conidia) and ITS sequencing as $H$. odoratus (anamorph C. mycophilum). This fungus is one of a group of closely related species which can cause cobweb disease of cultivated mushrooms such as the edible species $A$. bisporus, $P$. eryngii and $P$. ostreatus (see e.g. Back et al. 2012b; Tamm and Põldmaa 2013; Gea et al. 2014, 2016, 2019; Carrasco et al. 2016; Chakwiya et al. 2019). The species proliferates also on mushroom substrates (Grogan 2006; Carrasco et al. 2016; Gea et al. 2016, 2019) and has also been encountered on the polypores Ganoderma lucidum (Zuo et al. 2016) and Polyporus sp. in culture (Rogerson and Samuels 1994). In commercial button mushroom cultures, any mushrooms encountered will be engulfed by the mycopathogen with radial outgrowth of mycelium on the substrate (Grogan 2006; Muhammad et al. 2019). We have observed similar events in nature with the mycopathogens growing from the surroundings (decayed fungal material, decaying grass/moss, soil) onto the stipes of nearby developing $A$. xanthodermus structures (Fig. 3).

\section{Spread of $\boldsymbol{H}$. odoratus cobweb clones in nature}

Cobweb disease can be spread by airborne conidia. In mushroom-growing rooms, the large conidia are released from spore clusters on the colonies into the air by physical disturbances such as by watering. When subsequently landing and germinating on mushrooms, disease symptoms can be incurred (Dar 1997; Adie et al. 2006; Grogan 2006). Following initially a single infested mushroom (Figs. 1e-l, 2), we observed a larger outbreak of disease in nature after heavy rainfalls in the 3rd week of September 2015 in the 2nd flush of mushrooms of $A$. xanthodermus (Fig. 3). It is thus possible that the rainfall helped to distribute conidia from the place of the previous single mushroom infestation over the larger area, in addition to the general promotion of host and pathogen growth by providing good levels of humidity through rainfall to both. $H$. odoratus conidia do not survive long under dry conditions (Lane et al. 1991) and high humidity is needed for dispersal and germination (Carrasco et al. 2016, 2017). Attack of A. bisporus by H. odoratus in commercial cultures can happen at any stage in the fruiting body development (Carrasco et al. 2017; Chakwiya et al. 2019) while infections tend to become more severe on the crop in later flushes at longer time of cultivation and during autumn and winter cycles with increasing conidia numbers (Carrasco et al. 2016, 2017). Our observations on $A$. xanthodermus in nature resemble the reports on disease on $A$. bisporus in commercial mushroom production.

While $H$. odoratum is shown to produce perithecia with ascospores in culture (Arnold 1963; Põldmaa 2011; Tamm and Põldmaa 2013), it is not known to do so in nature. Clonality is expected to occur in nature of asexually reproducing Hypomyces species in course of spreading of conidia as a major mode of reproductive distribution (McKay et al. 1999; Grogan and Gaze 2000; Valdez and Douhan 2012; Tamm and Põldmaa 2013; Carrasco et al. 2017; Chakwiya et al. 2019). We isolated five $H$. odoratum strains from a close neighbourhood, three of a same infested fruiting body (AscoA1, AscoB1, AscoC1) but of different mushroom organs (from cap and stipe, respectively). Another isolate (AscoE1) came from a decaying stipe of a later infested mushroom. Their properties were very similar, in measurements only distinct in some minor details. The 5th strain (AscoD1) isolated from grass/moss was more different from the other four such as by slower growth speed, a stronger yellow colony colour and by lower spore production. This might suggest that they are not (all) clonal in relation to each other. Larger population field studies on $H$. odoratus in nature are currently missing in order to know how much genetic diversity exists in natural populations and whether sexual reproduction and recombination occurs in nature. Nearly identical clones have been isolated from commercial $A$. bisporus cultivations in different European countries and other continents. Using worldwide 
the same $A$. bisporus production strain and spawn and casing soils from same sources, this could however relate to human activities in mushroom cultivations if hygienic conditions were not strictly kept. Further alternative sources of primary infections in commercial mushroom cultures were by human movements and other material transport (Carrasco et al. 2017; Chakwiya et al. 2019). In contrast, clones from mushroom farms have in some instances been interlinked to local populations in nature (Tamm and Põldmaa 2013). There is thus also a possible danger for introduction of the pathogens into mushroom farms newly from the nature.

\section{Outbreaks and host range of $H$. odoratum cobweb}

Most of the present knowledge on the species $H$. odoratus/C. mycophilum comes from cobweb outbreaks experienced in newer time in commercial mushroom cultivations (see "Introduction"; Grogan 2006; Tamm and Põldmaa 2013). In essence, cobweb disease in mushroom cultures is caused by different species and up to recently, there was much confusion on species identities. $H$. odoratus/C. mycophilum was often mistaken by H. rosellus, a related species with similar disease symptoms. $H$. rosellus has however distinct conidiophores with a rachis at the apex of phialides, produces only two-celled conidia, has a more confined host-range and appears to be less often prevalent in the wild. In addition, the two species differ in their ITS sequences allowing to distinguish the two species further by molecular data why several misidentified strains were later reassigned to $H$. odoratus/C. mycophilum (McKay et al. 1999; Tamm and Põldmaa 2013). Our morphological and molecular data define the five strains isolated in this study from the wild clearly as $H$. odoratus.

$H$. odoratus has a very broad host range on mushrooms growing in nature in temperate regions (Tamm and Põldmaa 2013). Incidences of infections on agaric fruiting bodies in the wild have sporadically been recorded before for A. xanthodermus, Armillaria mellea, Calocybe gambosa, Cortinarius collinitus var. mucosis, Enteloma clypeatum, Hebeloma sp., Hygrophorus camarophyllus, Inocybe sp., Lycoperdon pyriforme, Megacollybia platyphylla, Mycena galericulata, Oudemannsiella platyphylla, Pholiota sp., Pseudoclitocybe cyathiformis, and Tricholoma terreum as well as occurrence on soil, leaf litter and rotting wood (Arnold 1963; Gams and Hoozemans 1970; Helfer 1991; Rogerson and Samuels 1994; Tamm and Põldmaa 2013). H. odoratus is considered to be agaricicolous (Rogerson and Samuels 1994) whereas other Hypomyces/Cladobotryum species are specified as boleticolous and polyporicolous (Rogerson and Samuels 1989, 1993; Tamm and Põldmaa 2013). However, Coniophora sp., Suillus aeruginascens and Suillus bovinus from the Boletales (Arnold 1963; Rogerson and Samuels 1994; Tamm and Põldmaa 2013), Albatrellus sp., Lactarius mitissimus, Lactarius deliciosus, Lactarius quietus, Lactarius cf. vellereus, Russula virescens, Russula sp., and Stereum sanguinolentum from the Russuales (Arnold 1963; Gams and Hoozemans 1970; Helfer 1991; Tamm and Põldmaa 2013), and Trametes versicolor from the Polyporales (Gray and Morgan-Jones 1980) are further named as potential hosts for H. odoratus in nature, as well as Cantharellus cibarius from the Cantharellales, Gloeophyllum sepiarium from the Gloeophyllales, and Clavariadelphus truncatus from the Gomphales (Helfer 1991). Newer observations on the species in nature with molecular identification would be helpful to unambiguously confirm these claims.

Other than the many incidences in commercial mushroom cultivations and the mostly older reports on occasional fungal collections in the wild, little is so far known on the ecology of necrotrophic Hypomyces species such as $H$. odoratus in nature. Our observations in nature and the infection tests in the laboratory confirm A. xanthodermus fruiting bodies to be susceptible to $H$. odoratus. The host range of the five isolated strains does not restrict to A. xanthodermus but include further Agaricus species. The strains grew on and quickly decayed commercial fruiting bodies of $A$. bisporus, in accordance with the various reports in the literature on occurrence of the species on the white button mushroom in cultivation (see "Introduction"; Grogan 2006; Tamm and Põldmaa 2013). The host range of the five strains extends also onto mushrooms of an Agaricus sp. from the section Arvenses but not particularly to fruiting bodies of $P$. ostreatus. Resistance against $H$. odoratus has been reported from infection tests for Hypsizygus marmoreus fruiting bodies (Back et al. 2012a, b, 2015) whereas F. velutipes (Back et al. 2012b), G. lucidum (Zuo et al. 2016), P. eryngii (Back et al. 2012b; Kim et al. 2014; Gea et al. 2011, 2014, 2016, 2017) and P. ostreatus (Pérez-Silva and Guevara 1999; Gea et al. 2019) were found to be (partially) susceptible. However, the place of inoculation can play a role. Upper parts of intact caps of $P$. eryngii were thus relatively resistant against $H$. odoratus infection while the pathogen could effectively attack mushrooms of the species through cuts (Gea et al. 2014, 2016). A recent report on infestation of $P$. ostreatus by $H$. odoratus revealed further that the bases of fruiting bodies of this species can be more sensitive against infections by the pathogen (Gea et al. 2019), similarly to our own observations on rare events of overgrowth of mushroom stipes of $P$. ostreatus (Fig. 9).

Mycelial proliferation of P. eryngii is hindered by $H$. odoratus and the species is attacked by the pathogen at any cultivation stage (Kim et al. 2014). Differently to 
the fruiting bodies, mycelium of $A$. bisporus has been reported to be resistant e.g. for the wet bubble disease inducer H. perniciosus (Zhang et al. 2017) while the dry bubble inducer L. fungicola has variably been found to attack or not attack host mycelium (Dragt et al. 1996; Calonje et al. 2000; Shamshad et al. 2009) and the cobweb inducer Cladobotryum varium overgrow with time cultures of the basidiomycete and caused necrosis (Gray and Morgan-Jones 1981). Furthermore shown in this study, in mycelial confrontations with growing or grown A. xanthodermus and P. ostreatus cultures, the five $H$. odoratus isolates here were not or not very aggressive with both species. In contrast, the strains more strongly attacked mycelial $C$. cinerea colonies. This latter species is a dung fungus that likes higher temperatures around $37^{\circ} \mathrm{C}$ best for growth (Kües 2000) while it is poorly growing at lower temperature ranges such as RT (Fig. 9). Strains of the temperate species $H$. odoratus grow in temperature ranges of 5 to $25{ }^{\circ} \mathrm{C}$ and only very poorly at warmer temperatures up to $28{ }^{\circ} \mathrm{C}$ (Back et al. 2012b). As seen in Fig. 3, strains of H. odoratus proliferate in nature from soil, plant litter and former mushroom residues onto their hosts. The two fungi $C$. cinerea and $H$. odoratus may live under quite different environmental circumstances and ecological niches why a species like $C$. cinerea with higher temperature preferences might not have developed a mycelial growth resistance at lower temperature towards this particular pathogen. As also seen in this study, $H$. odoratus does not generally infect all Agarics (Fig. 5) although the mycopathogen has an apparent preference for them. Other parasitic Hypomyces species appear to preferentially attack polypores and boletes (Rogerson and Samuels 1989, 1993). The broader host range is one criterium to distinguish Hypomyces species, temperature preferences another. $H$. odoratus and the also agaricicolous $H$. rosellus are adapted to temperate regions, whereas other Hypomyces species are found on mushrooms in the tropics and subtropics (Põldmaa 2011; Tamm and Põldmaa 2013). C. cinerea is an edible mushroom cultivated in some tropical countries including Thailand (Kües et al. 2007) and it could be of interest to test whether the species is better resistant against tropical Hypomyces species.

\section{Acknowledgements}

We are very grateful to Mojtaba Zomorrodi for technical help in fungal cultivations and pH measurements and to Bernd Kopka for providing climate data.

\section{Authors' contributions}

$\mathrm{KL}$, WK and UK observed mushrooms in nature, designed experiments, performed mycelial confrontation tests and analyzed data. KL performed most outdoor research, mushroom infection tests and strain isolations. WK did ITS analyses and provided most of the cell measurements. KL wrote a first draft of the paper. UK, KL and WK revised the manuscript. All authors read and approved the final manuscript.

\section{Funding}

Open access funding provided by Projekt DEAL. WK acknowledges a Ph.D. student grant from the Royal Thai government.

Availability of data and materials

Not applicable.

\section{Ethics approval and consent to participate}

This article does not contain any studies with human participants or any studies with animals.

\section{Consent for publication}

Not applicable.

\section{Competing interests}

All authors declare that they have no conflict of interest associated with this work.

\section{Author details}

${ }^{1}$ Department of Molecular Wood Biotechnology and Technical Mycology, Büsgen-Institute, Georg-August-University, Göttingen, Germany. ${ }^{2}$ Center for Molecular Biosciences (GZMB), Georg-August-University, Göttingen, Germany. ${ }^{3}$ Present Address: Faculty of Agricultural Technology, Rajabhat Mahasarakham University, Mueang Maha Sarakham District, Maha Sarakham, Thailand.

Received: 29 July 2020 Accepted: 8 August 2020

Published online: 13 August 2020

\section{References}

Adie B, Grogan H, Archer S, Mills P (2006) Temporal and spatial dispersal of Cladobotryum conidia in the controlled environment of a mushroom growing room. Appl Environ Microbiol 72:7212-7217

Arnold G (1963) Einige seltene Pilze auf Hymenomyceten. Z Pilzk 29:33-36

Ashley JN, Hobbs BC, Raistick H (1937) Studies in the biochemistry of microorganisms. LIII. The crystalline colouring of Fusarium culmorum (W.G. Smith) Sacc. and related forms. Biochem J 31:385-397

Back CG, Kim YH, Jo WS, Chung H, Jung HY (2010) Cobweb disease on Agaricus bisporus caused by Cladobotryum mycophilum in Korea. J Gen Plant Pathol 76:232-235

Back CG, Lee CY, Seo GS, Jung HY, Ohga S (2012a) First occurrence of cobweb disease on Hypsizigus marmoreus caused by Cladobotryum varium in Korea. J Fac Agric Hort Kyushu Univ 57:373-377

Back CG, Lee CY, Seo GS, Jung HY (2012b) Characterization of species of Cladobotryum which cause cobweb disease in edible mushrooms grown in Korea. Mycobiology 40:189-194

Back CG, Lee SY, Asaf S, Kang IK, Jung HY, Ohga S (2015) Identification and characterization of a new species, Cladobotryum hypsigum, that causes cobweb disease in beech mushroom (Hypsizygus marmoreus) in Korea. J Fac Agric Kyushu Univ 60:7-12

Badalyan SM, Szafranski K, Hoegger PJ, Navarro-Gonzaléz M, Majcherczyk A, Kües U (2011) New Armenian wood-associated coprinoid mushrooms: Coprinopsis strossmayeri and Coprinellus aff. radians. Diversity 3:136-154

Bailey KL, Falk S, Derby JA, Melzer M, Boland GJ (2013) The effect of fertilizers on the efficacy of the bioherbicide, Phoma macrostoma, to control dandelions in turfgrass. Biol Cont 65:147-151

Berendsen RL, Baars JJ, Kalkhove SI, Lugones LG, Wösten HA, Bakker PA (2010) Lecanicillium fungicola: causal agent of dry bubble disease in whitebutton mushroom. Mol Plant Pathol 11:585-595

Bernardo D, Cabo AP, Novaes-Ledieu M, Mendoza CG (2004) Verticillium disease or 'dry bubble' of cultivated mushrooms: the Agaricus bisporus lectin recognizes and binds the Verticillium fungicola cell wall glucogalactomannan. Can J Microbiol 50:729-735

Bhatt N, Singh RP (2002) Chemical control of myco-parasites of button mushroom. J Mycol Plant Pathol 32:38-45

Breitenbach J, Kränzlin F (1995) Pilze der Schweiz. Band 4 Blätterpilze 2. Teil. Entolomataceae, Pluteaceae, Amanitaceae, Agaricaceae, Coprinaceae, Bolbitiaceae, Strophariaceae. Mykologische Gesellschaft Luzern, Verlag Mykologia, Luzern, Switzerland 
Calonje M, Mendoza CG, Cabo AP, Bernardo D, Novaes-Ledieu M (2000) Interaction between the mycoparasite Verticillium fungicola and the vegetative mycelial phase of Agaricus bisporus. Mycol Res 104:988-992

Carrasco J, Navarro MJ, Santos M, Diánez F, Gea FJ (2016) Incidence, identification and pathogenicity of Cladobotryum mycophilum, causal agent of cobweb disease on Agaricus bisporus mushroom crops in Spain. Ann Appl Biol 168:214-224

Carrasco J, Navarro M-J, Gea FJ (2017) Cobweb, a serious pathology in mushroom crops: a review. Span J Agric Res 15:e10R01

Chakwiya A, Van der Linde EJ, Chidamba L, Korsten L (2019) Diversity of Cladobotryum mycophilum isolates associated with cobweb disease of Agaricus bisporus in the south African mushroom industry. Eur J Plant Pathol 154:767-776

Cole GT, Kendrick B (1971) Conidium ontogeny in Hyphomycetes: development and morphology of Cladobotryum. Can J Bot 49:595-599

Dar GM (1997) Studies on dispseral of cobweb disease of cultivated white button mushroom. Res Dev Rep 14:43-48

Douhan GW, Rizzo DM (2003) Host-parasite relationships among bolete infecting Hypomyces species. Mycol Res 107:1342-1349

Dragt JW, Geels FP, De Bruijn WC, Van Griensven LJLD (1996) Intracellular infection of the cultivated mushroom Agaricus bisporus by the mycoparasite Verticillium fungicola var. fungicola. Mycol Res 100:1082-1086

Fletcher JT, Jaffe B, Muthumeenakshi S, Brown AE, Wright DM (1995) Variations in isolates of Mycogone perniciosa and in disease symptoms in Agaricus bisporus. Plant Pathol 44:130-140

Gams W, Hoozemans ACM (1970) Cladobotryum—Konidienformen von Hypomyces-Arten. Persoonia 6:95-110

Gea FJ, Tello JC, Navarro MJ (2003) Occurrence of Verticillium fungicola var. fungicola on Agaricus bitorquis mushroom crops Spain. J Phytopathol 151:98-100

Gea FJ, Navarro MJ, Suz LM (2011) First report of Cladobotryum mycophilum causing cobweb on cultivated king oyster mushroom in Spain. Plant Dis 95:1030

Gea FL, Carrasco J, Santos M, Diánez F, Navarro M (2014) Cladobotryum mycophylum, causal agent of cobweb disease on commercial Agaricus bisporus and Pleurotus eryngii crops in Spain. In: Proceedings of the 8th international conference on mushroom biology and mushroom products (ICMBMP8), New Delhi, India, 19-22 November 2014, Volume I \& II, pp 523-529. https://www.cabdirect.org/cabdirect/FullTextPD F/2015/20153365535.pdf

Gea FJ, Carrasco J, Suz LM, Navarro MJ (2016) Characterization and pathogenicity of Cladobotryum mycophilum in Spanish Pleurotus eryngii mushroom crops and its sensitivity to fungicides. Eur J Plant Pathol 147:129-139

Gea FJ, Carrosco J, Suz LM, Navatto MJ (2017) Characterization and pathogenecity of Cladobotryum mycophilum in Spanish Pleurotus eryngii mushroom crops and its sensitivity to fungicides. Eur J Plant Pathol 147:129-139

Gea FJ, Navarro MJ, Suz LM (2019) Cobweb disease on oyster culinarymedicinal mushroom (Pleurotus ostreatus) caused by the mycoparasite Cladobotryum mycophilum. J Plant Pathol 101:349-354

Geml J, Geiser DM, Royse DJ (2004) Molecular evolution of Agaricus species based on ITS and LSU rDNA sequences. Mycol Progr 3:157-176

Gill M, Strauch RJ (1984) Constituents of Agaricus xanthodermus Genevier: The first naturally endogenous azo compound and toxic phenolic metabolites. Z Naturforsch 39c:1027-1029

Glamoclija J, Soković M, Ljaljević-Grbić M, Vukojević J, Milenković I, Van Griensven L (2008) Morphological characteristics and mycelial compatibility of different Mycogone perniciosa isolates. J Microsc 232:489-492

Granado JD, Kertesz-Chaloupková K, Aebi M, Kües U (1997) Restriction enzyme-mediated DNA integration in Coprinus cinereus. Mol Gen Genet 256(1):28-36

Gray DJ, Morgan-Jones G (1980) Notes on Hyphomycetes. XXXIV. Some mycoparasitic species. Mycotaxon 10(2):375-404

Gray DJ, Morgan-Jones G (1981) Host-parasite relationships of Agaricus brunnescens and a number of mycoparasitic hyphomycetes. Mycopathologia 75:55-59

Grogan HM (2006) Fungicide control of mushroom cobweb disease caused by Cladobotryum strains with different benzimidazole resistance profiles. Pest Manag Sci 62:153-161
Grogan HM, Gaze RH (2000) Fungicide resistance among Cladobotryum spp.-Causal agents of cobweb disease of the edible mushroom Agaricus bisporus. Mycol Res 104:357-364

Helfer W (1991) Pilze auf Pilzfruchtkörpern. Untersuchungen zur Ökologie, Systematik und Chemie. Libri Botanici 1, IHW-Verlag, Eching, Germany

Hughes SJ (1958) Revisiones Hyphomycetum aliquot cum appendice de nominibus rejiciendis. Can J Bot 36:727-836

Kerrigan RW, Callac P, Guinberteau J, Challen MP, Parra LA (2005) Agaricus section xanthodermatei: a phylogenetic reconstruction with commentary on taxa. Mycologia 97:1292-1315

Kertesz-Chaloupková K, Walser PJ, Granado JD, Aebi M, Kües U (1998) Blue light overrides repression of asexual sporulation by mating type genes in the basidiomycete Coprinus cinereus. Fungal Genet Biol 23:95-109

Kim TS, Lee HW, Song GW, Shin WG (1998) King oyster mushroom (Pleurotus eryngii) white mold disease caused by Cladobotryum varium. Korean Soc Mycol News Lett 11:46

Kim HK, Seok SJ, Kim GP, Moon BJ, Terashita T (1999) Occurrence of disease caused by Cladobotryum varium on Flammulina velutipes in Korea. Korean J Mycol 27:415-419

Kim MK, Lee YH, Cho KM, Lee JY (2012) First report of cobweb disease caused by Cladobotryum mycophilum on the edible mushroom Pleurotus eryngii in Korea. Plant Dis 96:1374

Kim MK, Seuk SW, Lee YH, Kim HR, Cho KM (2014) Fungicide sensitivity and characterization of cobweb disease on a Pleurotus eryngii mushroom crop caused by Cladobotryum mycophilum. Plant Pathol J 30:82-89

Kirschner R, Arnold GRW, Chen CJ (2007) Cladobotryum semicirculare sp. nov. (Hyphomycetes) from commercially grown Ganoderma tsugae in Taiwan and other Basidiomycota in Cuba. Sydowia 59:114-124

Kouser S, Shah S (2013) Isolation and identification of Mycogone perniciosa, causing wet bubble disease in Agaricus bisporus cultivation in Kashmir. Afr J Agric Res 8:4804-4809

Kües U (2000) Life history and the developmental processes in the basidiomycete Coprinus cinereus. Microbiol Mol Biol Rev 64:316-353

Kües U, Navarro-Gonzaléz M, Srivilai P, Chaisaena W, Velagapudi R (2007) Mushroom biology and genetics. In: Kües U (ed) Wood production, wood technology, and biotechnological impacts. Universitätsverlag Göttingen, Göttingen, pp 587-607

Lakkireddy K, Khonsuntia W, Kües U (2016) Mycoparasites isolated from Agaricus macrosporus in nature. In: Baars JJP, Sonnenberg ASM (eds) Science and cultivation of edible fungi: mushroom science IXX. International Society for Mushroom Science, Amsterdam, pp 118-121

Lane CR, Cooke RC, Burden LJ (1991) Ecophysiology of Dactylium dendroidesthe causal agent of cobweb mould. Sci Cult Edible Fungi 13:365-372

Laperriere G, Desgagne-Penix I, Germain H (2018) DNA distribution pattern and metabolite profile of wild edible lobster mushmoom (Hypomyces lactifluorum/Russula brevipes). Genome 61:329-336

Largeteau ML, Savoie JM (2010) Microbially induced diseases of Agaricus bisporus: biochemical mechanisms and impact on commercial mushroom production. Appl Microbiol Biotechnol 86:63-73

Largeteau ML, Regnault-Roger C, Savoie JM (2007) Verticillium disease of Agaricus bisporus: variations in host contribution to total fungal DNA in relation to symptom heterogeneity. Eur J Plant Pathol 118:155-164

Lee CY, Park JE, Lee J, Kim JK, Ro HS (2011) Development of new strains and related SCAR markers for an edible mushroom, Hypsizygus marmoreus. FEMS Microbiol Lett 327:54-59

Marlowe A, Romaine CP (1982) Dry bubble of oyster mushroom caused by Verticillium fungicola. Plant Dis 66:859-860

Marzuko NF, Goh YK, Tung HJ, Goh YK, Goh KJ (2015) Evaluation on the cultural characteristics and antagonistic activities of Cladobotryum semicirculare against Ganoderma boninense in vitro. J Oil Palm Res 27:326-338

McKay GJ, Egan D, Morris E, Scott C, Brown AE (1999) Genetic and morphological characterization of Cladobotryum species causing cobweb disease of mushrooms. Appl Environ Microbiol 65:606-610

Muhammad I, Sossah FL, Yang Y, Li D, Li S, Fu Y, Li Y (2019) Identification of resistances to cobweb disease caused by Cladobotryum mycophilum in wild and cultivated strains of Agaricus bisporus and screening for bioactive botanicals. RCS Adv 9:14758-14765

Naumann A, Navarro-González M, Sánchez-Hernández O, Hoegger PJ, Kües U (2007) Correct identification of wood-inhabiting fungi by ITS analysis. Curr Trends Biotechnol Pharm 1:41-61 
North LH, Wuest PJ (1993) The infection process and symptom expression of Verticillium disease of Agaricus bisporus. Can J Plant Pathol 15:74-80

Nunes JD, De Brito MR, Zied DC, Leite EAD, Es Dias, Alves E (2017) Evaluation of the infection process by Lecanicillium fungicola in Agaricus bisporus by scanning electron microscopy. Rev Iberoam Micol 34:36-42

Parrag V, Felföldi J, Baranyai L, Geösel A, Firtha F (2014) Early detection of cobweb disease infection on Agaricus bisporus sporocarps using hyperspectral imaging. Acta Aliment 43:107-113

Pérez-Silva E, Guevara EB (1999) Hongos micoparásitos II. Especies del Estado de México. Ciencia Ergo Sum 6:285-289

Petrova A, Alipieva K, Kostadinova E, Antonoby D, Lacheva M, Gjosheva M, Popov S, Bankova C (2007) GC-MS studies of the chemical composition of two inedible mushrooms of the genus Agaricus. Chem Cent J 1:33

Põldmaa K (2003) Three species of Hypomyces growing on basidiomata of Stereaceae. Mycologia 95:921-933

Põldmaa K (2011) Tropical species of Cladobotryum and Hypomyces producing red pigments. Stud Mycol 68:1-34

Põldmaa K, Samuels GJ (1999) Aphyllophoricolous species of Hypomyces with KOH-negative perithecia. Mycologia 91:177-199

Potočnik I (2006) Morphological and pathogenic characteristics of the causal agents of dry and wet bubble diseases of white button mushroom (Agaricus bisporus (Lange) Imbach) in Serbia. Pesticidii Fitomedicina 21:289-296

Rogerson CT, Samuels GJ (1989) The boleticolous species of Hypomyces. Mycologia 81:413-432

Rogerson CT, Samuels GJ (1993) Polyporicolous species of Hypomyces. Mycologia 85:231-272

Rogerson CT, Samuels GJ (1994) Agaricicolous species of Hypomyces. Mycologia 86:839-866

Shamshad A, Clift AD, Mansfield S (2009) Host-parasite interaction between cultivated mushroom, Agaricus bisporus hybrid strain Sylvan A15, and the mycoparasite Verticillium fungicola, a causal agent of dry bubble disease. Aust Plant Pathol 38:74-78

Sharma SR, Kumar S (2000) Studies on wet bubble disease of white button mushroom (Agaricus bisporus), caused by Mycogone perniciosa. Mushroom Sci 15:569-575

Sharma VP, Kamal S, Kumar S (2015) Genetic diversity, enzyme profiles and yield loss due to Cladobotryum isolates associated with cob web disease of edible mushrooms. Sydowia 67:65-74

Sisto D, Faggiano S, Rana GL (1997) Mycogone perniciosa, a potential threat for cultivated mushrooms in southern Italy. Petria 7:159-164

Sohi HS, Upadhyay RC (1986) Occurrence of Cladobotryum variospermum (Link) Hughes on polyporous fungi under natural conditions. Curr Sci 55:1037-1038

Soković M, Van Griensven LJLD (2006) Antimicrobial activity of essential oils and their components against the three major pathogens of the cultivated button mushroom, Agaricus bisporus. Eur J Plant Pathol 3:211-224

Soler-Rivas C, Espín JC, Wichers HJ (2000) An easy and fast test to compare total free radical scavenger capacity of foodstuffs. Phytochem Anal 11:330-338
Swamy S, Uno I, Ishikawa T (1984) Morphogenetic effects of mutations at the $A$ and $B$ incompatibility factors in Coprinus cinereus. J Gen Microbiol 130:3219-3224

Szumigaj-Tarnowska J, Ślusarski C, Uliński Z (2015) Pathogenicity of Mycogone perniciosa isolates collected on polish mushroom farms. J Hortic Res 23:87-92

Tamm H, Põldmaa K (2013) Diversity, host associations and phylogeography of temperate aurofusarin-producing Hypomyces/Cladobotryum including causal agents of cobweb disease of cultivated mushrooms. Fungal Biol 117:348-367

Umar MH, Van Griensven LJLD (1999) Studies on the morphogenesis of Agaricus bisporus: the dilemma of normal versus abnormal fruit body development. Mycol Res 103:1235-1244

Umar MH, Geels FP, Van Griensven LJLD (2000) Pathology and pathogenesis of Mycogone perniciosa infection of Agaricus bisporus. Mushroom Sci 15:561-567

Valdez GU, Douhan GW (2012) Geographic structure of a bolete-infecting cryptic species within the Hypomyces microspermus species complex in California. Mycologia 104:14-21

Waalwijk C, de Koning JRA, Baayen RP, Gams W (1996) Discordant groupings of Fusarium spp. from the sections Elegans, Liseola and Dlaminia based on ribosomal ITS1 and ITS2 sequences. Mycologia 88:361-368

Wang GZ, Guo MP, Bian YB (2015) First report of Cladobotryum protrusum causing cobweb disease on the edible mushroom Coprinus comatus. Plant Dis 99:287

White TJ, Bruns T, Lee S, Taylor J (1990) Amplification and direct sequencing of fungal ribosomal RNA genes for phylogenetics. In: Innis MA, Gelfand DH, Sninsky JJ, White TJ (eds) PCR protocols: a guide to methods and applications. Academic Press, San Diego, pp 315-322

Zare R, Gams W (2008) A revision of the Verticillium fungicola species complex and its affinity with the genus Lecanicillium. Mycol Res 112:811-824

Zare R, Gams W (2016) More white verticillium-like anamorphs with erect conidiophores. Mycol Prog 15:993-1030

Zhang C, Kakishima N, Xu J, Wang Q, Li Y (2017) The effect of Hypomyces perniciosus on the mycelia and basidiomes of Agaricus bisporus. Microbiology 163:1273-1281

Zolan ME, Pukkila PJ (1986) Inheritance of DNA methylation in Coprinus cinereus. Mol Cell Biol 6:195-200

Zuo B, Lu BH, Liu XL, Wang Y, Ma GL, Gao J (2016) First report of Cladobotryum mycophilum causing cobweb on Ganoderma lucidum cultivated in Jilin Province, China. Plant Dis 10:1094

\section{Publisher's Note}

Springer Nature remains neutral with regard to jurisdictional claims in published maps and institutional affiliations.

\section{Submit your manuscript to a SpringerOpen ${ }^{\odot}$ journal and benefit from:}

- Convenient online submission

- Rigorous peer review

- Open access: articles freely available online

- High visibility within the field

- Retaining the copyright to your article

Submit your next manuscript at $\boldsymbol{\nabla}$ springeropen.com 